\title{
1 Drug delivery across length scales
}

2 Derfogail Delcassian, ${ }^{\mathrm{a}, \mathrm{b}, \mathrm{c}}$ Asha K. Patel, ${ }^{\mathrm{a}, \mathrm{d}}$ Abel B. Cortinas, ${ }^{\mathrm{a}, \mathrm{e}}$ Robert

3 Langer ${ }^{\mathrm{a}, \mathrm{e}, \mathrm{f}, \mathrm{g}} *$

$4 \quad{ }^{a}$ David H. Koch Institute for Integrative Cancer Research, Massachusetts Institute of

5 Technology, Cambridge, MA, USA;

$6{ }^{b}$ Department of Anaesthesiology, Boston Children's Hospital, Harvard Medical School,

7 Boston, MA, USA;

$8{ }^{c}$ Division of Regenerative Medicine and Cellular Therapies, School of Pharmacy,

9 University of Nottingham, Nottingham, UK;

$10{ }^{d}$ Division of Cancer and Stem Cells, School of Medicine, and Division of Advanced

11 Materials and Healthcare Technologies, School of Pharmacy, University of

12 Nottingham, UK.

13 e Department of Chemical Engineering, Massachusetts Institute of Technology,

14 Cambridge, MA, USA

15 Institute for Medical Engineering and Science, Massachusetts Institute of Technology,

16 Cambridge, MA, USA

$17{ }^{g}$ Media Lab, Massachusetts Institute of Technology, Cambridge, MA, USA;

18

$19 *$ corresponding author; Robert Langer; rlanger@mit.edu 


\section{Drug delivery across length scales}

23

24

25

26

27

28

29

30

31

32

33

34

35

36

37

Over the last century there has been a dramatic change in the nature of therapeutic, biologically active molecules available to treat disease. Therapies have evolved from extracted natural products towards rationally designed biomolecules, including small molecules, engineered proteins, and nucleic acids. The use of potent drugs which target specific organs, cells, or biochemical pathways, necessitates new tools which can enable controlled delivery and dosing of these therapeutics to their biological targets. Here, we review the miniaturisation of drug delivery systems from the macro- to nano- scale, focusing on controlled dosing and controlled targeting as two key parameters in drug delivery device design. We describe how the miniaturisation of these devices enables the move from repeated, systemic dosing, to on demand, targeted delivery of therapeutic drugs, and highlight areas of focus for the future.

Keywords: drug delivery; length scale; targeting; macro; micro; nano 
Over the last century there has been a dramatic change in the nature of therapeutic,

40 biologically active molecules available to treat disease. This is represented by the move from extracted natural products and synthesised natural product mimics ${ }^{1}$, towards rationally designed biomolecules including small molecules, engineered proteins, and nucleic acids ${ }^{2-4}$. The evolution of potent drugs which target specific organs, cells, or biochemical pathways, necessitates new tools which can enable controlled delivery and dosing of these therapeutics to their biological targets. Therapies which can be administered as a single procedure, either through the delivery of a single dose of a potent curative therapeutic, or through the implantation of a device that can maintain a precise, long term drug dosing regime, are highly desired.

Macro-scale drug delivery devices have been widely adopted since the 1970s, when long-acting intra-uterine contraceptive implants were offered as an alternative to daily repeated oral administration of systemically released hormones ${ }^{5}$. These implants could be inserted during a single procedure, and remained effective for several years through localised and controlled release of contraceptive hormones. Since then, a wide range of systems for therapeutic drug delivery have been developed, broadly focused on systems which can help to regulate drug dosing ${ }^{6}$, and those which aid targeted delivery for site-specific therapeutic action ${ }^{7-10}$. Drug delivery devices are in widespread clinical use, however, many of these systems are limited in their ability to deliver therapeutics to smaller biological structures with control over both drug dosing and therapeutic targeting. dramatically impact therapeutic efficacy. In vaccination, the timing of drug dosing (e.g. 
62 the dosing regimen as well as the time of day) is an important parameter in the

63 development of robust immunity ${ }^{11}$. Drug dosing is therefore a crucial consideration in drug delivery device design, and many strategies have been explored to regulate dosing; including continuous, controlled release systems ${ }^{7,12-15}$, enhanced therapeutic circulation time $^{16,17}$ and stimuli responsive drug administration ${ }^{7,18-22}$. Separately, as therapeutic targets become increasingly specific, and therapies become increasingly potent, delivering site specific therapeutic action becomes a more critical design feature. Control over both of these aspects can improve patient safety, quality of life and compliance by lessening the stringent requirements of strict medication schedules and reducing off-target effects.

Here, we review drug delivery systems across the macro- to nano- scale, highlighting systems which enable controlled dosing, and those which aid drug targeting. We explore the role of length scale in the function of these systems, considering macro-, micro- and nano- systems which are capable of delivery to organs, cells and cellular substructures of interest (Figure 1). We describe how the miniaturisation of these devices enables the move from repeated, systemic dosing, to on demand, targeted delivery of therapeutic drugs, and consider areas of future interest.

\section{MACRO SCALE DELIVERY SYSTEMS}

Macro scale delivery systems, measuring from $1 \mathrm{~mm}$ upwards in size, are particularly suited for long-term drug delivery. Their scale allows a single device to contain a considerable therapeutic reservoir, and enables precise engineering of accompanying parts required for more complex controlled drug administration, such as pumps, batteries, catheters and sensors ${ }^{23,24}$. For effective systemic drug delivery, drugs must first traverse the body's natural physical barriers and reach the systemic circulation, 
which can prove challenging for macro scale devices ${ }^{25}$. A number of approaches have been used to address this challenge, with examples including ingestible devices ${ }^{26-28}$, topical delivery through transdermal systems ${ }^{29-32}$, controlled release implants inserted close to vasculature ${ }^{6}$, and infusion pump systems which are connected to the systemic circulatory system via cannula or catheter ${ }^{23}$. Here, we review a range of macro scale drug delivery devices, and discuss how their scale impacts their ability to deliver therapeutics.

\section{Systemic delivery systems}

\section{Ingestible devices}

Ingestion is one of the most convenient administration routes for devices small enough to pass through the oesophagus ${ }^{25}$. Although a widely used drug delivery route, ingestion based delivery mechanisms have typically had limited usefulness in long term and controlled delivery systems, due to frequent gastric emptying times of between 2-3 hours $^{33}$. To combat this, several approaches have been developed to improve gastric retention times for macro devices small enough to swallow. These approaches focus on retaining devices within the stomach to provide continuous, systemic drug release, through adhesion to the stomach wall or changes in device geometry. In one example, macro devices composed of drug eluting polymers can be folded into a capsule small enough to swallow, which then expands in the stomach. These low density, floating devices are buoyant, and cannot pass through the pyloric sphincter and into the intestines $\operatorname{intact}^{28,33-35}$. Inclusion of a biodegradable moiety allows the devices to slowly degrade in vivo, and subsequently passage through the gastro intestinal tract post drug delivery. Advances in device design will enable systems to be retained beyond the current limit of a few months, potentially allowing longer term macro scale delivery systems which can 
110 be administered without surgical intervention. Although ingestible devices offer a robust

111 controlled delivery system that can passage through the gastro intestinal (GI) system,

112 orally delivered drugs must first be absorbed through the gut to become bioavailable. The

113 GI tract consists of the stomach, small intestine (duodenum, jejunum and ileum), the large

114 intestine (colon), and the rectum; drug absorption can occur across the entire GI tract. The

115 majority of drug absorption is occurs via the highly adapted microvilli in the small

116 intestine, however class III/IV drugs have been shown to preferentially absorb across the

$117 \operatorname{colon}^{36}$. Several drug delivery systems utilise the distinct chemical environments present

118 in specific regions of the gastrointestinal tract to facilitate a more targeted drug delivery

119 approach, discussed in detail in the targeted delivery section below. Regardless of

120 absorption site, orally administered drugs are subject to first-pass metabolism and hepatic

121 clearance, and so systemic bioavailability of a therapeutic drug concentration may be

122 lower when compared to intravenous administration.

123 Transdermal delivery

124 In contrast to ingestible devices, transdermal drug delivery methods offer many benefits

125 over the more traditionally administered oral route ${ }^{37}$. Firstly, compared to orally

126 delivered pharmacologics of the same dose, they can provide increased levels of

127 circulating, bioavailable drugs. This leads to a reduction in the drug dose needed to

128 elicit a specific pharmacological effect ${ }^{38-40}$, and can therefore reduce side effects.

129 Transdermal patches provide a controlled release system which is well suited to the

130 delivery of small molecules, though dermal penetration and delivery efficacy is affected

131 by both the molecular size and hydrophilicity of the therapeutic being administered.

132 Transdermal patches have been widely used to deliver small molecules such as nicotine

133 in smoking cessation therapies ${ }^{41}$, and contraceptive/postmenopausal hormones such as

134 estradiol and estrone ${ }^{38}$. Drug delivery patches are well suited for the continuous, 
135 systemic delivery of low dose therapeutics. Drug delivery profiles range from a few

136 days to a few weeks due to limitations in drug loading capacity, and patches must

137 remain attached to the skin for the duration of delivery.

\section{Polymer implants}

139 Implantable polymer devices have been in use since the 1970's for longer term systemic

140 drug delivery. Early examples included the Norplant ${ }^{\circledR}$ and Jadelle® non-degradable

141 subcutaneous contraceptive implants, which provided controlled release of

142 contraceptive hormones over 5 years. Early devices were composed of an implanted

143 polymer-drug composite coated with a porous ethyl vinyl acetate membrane ${ }^{42-44}$. This

144 membrane facilitated controlled kinetic release of the hormones, and similar devices

145 have been used to systemically deliver a range of pharmaceuticals including anti-

146 inflammatory drugs and antibiotics ${ }^{45-48}$. As with the early Norplant ${ }^{\circledR}$ devices, many of

147 these systems are based on non-degradable polymers with a fixed-rate delivery profile,

148 controlled by drug diffusion from within the device. Devices are usually implanted, and

149 removed, via a minor surgical procedure at the end of their delivery lifetimes. To

150 minimise surgical intervention required in the removal of these devices, longer-acting,

151 degradable subcutaneous rod implants are currently in development ${ }^{49}$.

152 In a similar approach, polymer hydrogel systems can be used for kinetically

153 controlled systemic drug release ${ }^{7,13,50}$. Hydrogels have the potential to deliver virtually

154 any therapeutic ${ }^{13,51}$; controlled release parameters are widely tuneable, with the nature

155 of the hydrogel crosslinking determining the kinetics of controlled release and the

156 biodegradability of the system. Both chemical (covalent) and physical (electrostatic

157 assembly, stereo-complexation, supramolecular host-guest inclusion) crosslinking can

158 be used to form hydrogel structures, however care must be taken to ensure the

159 crosslinking agent does not impact drug potency. The wide range of cross-linking 
160 chemistries and polymer compositions provides tuneable delivery profiles that can last

161 from several days up to several years, making polymer implants a versatile class of

162 materials for drug delivery.

163 Pump systems

164 A number of implantable infusion pump systems have been developed for long-term

165 delivery of therapeutics with metered dosing ${ }^{23}$. These devices can measure up to $10 \mathrm{~cm}$

166 in diameter, and are often surgically implanted into patients. They generally consist of a

167 reservoir-pump system which offers dosing schedules based on continuous fixed rate

168 delivery, timed dose delivery, or on-demand delivery in response to specific stimuli.

169 Dosing is usually controlled by an integrated pump system, which can be driven

170 through mechanical, peristaltic means ${ }^{52-55}$, propellant systems ${ }^{56-59}$, or is driven by

171 osmosis/diffusion ${ }^{60}$. Due to the invasive surgical nature of implantation, these devices

172 are primarily used for continuous therapeutic release in chronic medical conditions ${ }^{54,56 \text {, }}$

$173 \quad 57$. Examples include intrathecal delivery of opioid based analgesic therapies, or delivery

174 of muscle relaxants such as baclofen in patients with severe contractions. This

175 continuous, metered dosing is particularly useful for analgesics in long term and

176 palliative care, where the risk of misadministration and accidental overdose, a current

177 concern with prescribed opioid tablets, can be reduced.

178 For metered and on-demand dosing, stimuli responsive pumps can be used.

179 These have proven particularly useful in diabetes, where sensors implanted under the

180 skin can monitor and respond to glucose levels (MiniMed, Paradigm ${ }^{\circledR}$ Revel $\left.^{\mathrm{TM}}\right)^{61}$. In

181 these systems, reservoirs containing insulin, or twin reservoirs containing insulin and

182 glucagon, are connected to sensors and facilitate metered drug delivery in response to

183 hypo- or hyper-glycaemic events. Recently, wireless, smartphone connected sensors 
184 have been developed which allow patients and healthcare professionals to manage

185 glucose levels in real time ${ }^{62,63}$. These devices enable a truly patient specific, on-demand

186 therapy, and are now clinically used in systemic applications ${ }^{60,62,64}$. However, the

187 reservoir-based systems described limits the drug formulations to liquid systems, and

188 device lifetimes are limited by the reservoir loading capacity. Additionally, the use of a

189 power source to run the pumps in peristaltic devices limits the usefulness of these

190 devices due to short battery lifetimes (usually limited to 4-7 years) ${ }^{65}$. Finally, due to

191 their scale these more complex systems currently remain unsuitable for targeted or

192 localised delivery approaches, which require smaller scale devices.

\section{Localised delivery systems}

\section{Proximal polymer implants}

195 Many smaller macro scale devices can be surgically implanted within target organs to

196 allow for proximal drug release, enabling therapeutic efficacy using lower doses than

197 required in systemic delivery systems. A widespread example are contraceptive devices

198 introduced into the body via the vaginal tract. Contraceptive devices, briefly discussed

199 earlier, are widely adopted clinically, and intra uterine devices (IUDs) ${ }^{5}$ have been in

200 widespread use since the 1970s. IUDs and contraceptive vaginal rings can both be

201 applied via a minor surgical procedure, and systems such as the NuvaRing® and

202 Nestorone ${ }^{\circledR}$ offer controlled release on the order of 1 month to 3 years ${ }^{66,67}$ before

203 removal. For increased efficacy and reduced side effects, new progestin-infused rings

204 or combination drug devices that include both progesterone and estrogenic steroids are

205 in development ${ }^{66}$. Future developments are focused on combining localised

206 contraceptive drug release with systemic drug release, providing a multiplexed system

207 to reduce the risk of sexually transmitted infections ${ }^{67,68}$ in a vaginal ring device. 
To reach less accessible target organs, surgical intervention is often required to position macro devices correctly. A number of polymer-based macro devices are indicated for controlled drug delivery to target organs, exemplified by stent-based ${ }^{69}$

211 drug delivery. Stents are used for drug delivery in coronary interventions, and

212 additionally in non-vascular target organs including the oesophagus, biliary duct,

213 trachea, bronchi, sinus cavities, ureters, and urethra ${ }^{70,71}$. First-generation vascular stents

214 were approved by the FDA in 1994, and were manufactured from bare metal alloys or

215 ceramic composites. However, these stents caused complications including hyperplastic

216 growth and restenosis. Next generation stents therefore included novel metallic and

217 polymeric stent materials with more open mesh-like frameworks, and simultaneously

218 eluted anti-inflammatory drugs ${ }^{71,72}$ to reduce restenosis. Stents often provide a physical

219 support coupled with drug eluting capabilities. The continued optimisation of stent

220 structures to reduce plaque prolapse (through increased radial strength) and increase

221 biocompatibility (using fluoropolymer materials) renders these devices as versatile tools

222 for the delivery of a diverse class of drugs. Many systems have been developed for the 223 controlled delivery of anti-inflammatory, antimicrobial, and analgesic drugs ${ }^{70,71}$ using 224 diffusion based release profiles.

In contrast, less rigid polymer systems, have been used for non-structural drug delivery. Both biodegradable polymer stents, and implantable hydrogel systems can be used for localised therapeutic delivery. Biodegradable polymer systems are particularly useful for non-structural drug delivery systems ${ }^{70}$, as they can be packed into surgical sites and release drugs during healing before being resorbed into the body. These

230 polymer systems have been used in applications ranging from advanced wound healing

231 to the delivery of chemotherapeutics ${ }^{73,74}$. In contrast, macro scale polymer-based 232 hydrogel systems are useful for both surgical and non-surgical drug administration. A 
233 widespread example is hydrogel contact lenses used for ocular drug delivery. These

234 devices can increase the bioavailability of drugs otherwise limited by burdensome ocular administration dosing regimens ${ }^{48,75}$. They have proven particularly useful for delivery of medications for eye diseases including glaucoma, and delivery of antibacterial agents to the eye $\mathrm{e}^{76-78}$. In general, hydrogel thickness can be used to control

238 drug loading, and delivery profiles can be tuned to offer zero-order release kinetics.

239 Many hydrogel systems are unsuitable for localised ocular delivery applications due to 240 their limited transparency, stability, and the use of non-biocompatible crosslinking 241 agents during formation. Drug delivery contact lenses must be designed to possess

242 luminous transmittance, oxygen permeability, mechanical stability, and

243 biocompatibility ${ }^{76-79}$ in addition to their drug loading capacity. These stringent material 244 requirements highlight the complexities in designing drug delivery systems which match localised tissue requirements. Next, we discuss advances in macro scale drug delivery systems which enable a more targeted delivery approach.

\section{Targeted delivery systems}

248 Targeted delivery systems, where a device enables the delivery of a therapeutic to a 249 target organ or cell based in a different location to the administration site, are relatively 250 limited in macro scale devices. Due to their scale, macro devices are often too large to engage with many biological structures and target cells. A notable exception to this is the use of stimuli responsive macro scale devices for delivery to chemically distinct regions of the gastrointestinal tract ${ }^{34,80-82}$. The chemical environment of the stomach often poses a challenge to $\mathrm{pH}$ sensitive and enzymatically degraded protein and peptide therapeutics. Drug delivery devices frequently utilise local variations in target tissue $\mathrm{pH}$ to control drug release, with hydrogels sensitive to alkali $\mathrm{pH}$ and enteric tablet coatings

257 facilitating delivery to the intestines. 
258 For many other target tissues, macro scale devices are too large to travel through the

259 vasculature or lymphatic system and move towards target organs. In an alternative

260 approach, macro devices which can recruit a target cell towards the device to selectively

261 deliver a therapeutic drug to a target cell type have been developed. These devices have

262 been trialled in vaccination systems, where chemokines (CXCL12) have been

263 incorporated into a polymer material to encourage the recruitment of immune cells.

264 Once the immune cells reach the macro device, they "collect" the drug. In this way, the

265 macro device can overcome the transport limitation imposed due to its size, and

266 provides a targeted delivery system to specific cells by recruiting the cell of interest ${ }^{83-85}$

267 to the device location. This relatively new concept offers promise for the design of a

268 range of macro devices which can act in a targeted manner

\section{Summary}

270 Macro scale devices and their component parts can be precisely engineered to allow fine

271 control over drug dosing schedules, and in some cases, can be coupled with sensor

272 technology to enable patient specific systemic drug release. The dimensions of most

273 macro scale devices and their capacity to hold large therapeutic reservoirs renders them

274 suitable to long term drug delivery. However, these dimensions also limit their

275 usefulness in targeting smaller biological structures. Although some smaller macro

276 devices can be surgically inserted into larger target organs (i.e. uterus, large arteries) to

277 facilitate proximal or localised drug release, devices cannot migrate through the body,

278 limiting their ability to deliver drugs in a targeted fashion. The advent of new polymer

279 implants which can directly recruit target cells offers the potential to combine the

280 intrinsic advantages of macro devices (drug loading capacity, precision engineering,

281 patient specific stimuli responsive systems) with the targeting advantages usually found 
282 in smaller scale systems, and is an exciting future direction for macroscale device 283 development.

\section{MICRO SCALE DELIVERY SYSTEMS}

285 Devices at the micron scale range from 1-1000 $\mu \mathrm{m}$, allowing them to be introduced 286 within the body without the need for a major surgical procedure through ingestion

287 (orally administered osmotic pumps) $24,86,87$, inhalation, and inoculation (microparticles, 288 microneedles $)^{88-92}$. Many key biological structures are organised on the micron length 289 scale, with cells themselves measuring from 5-20 microns in diameter and possessing 290 cellular substructures on the order of nano- to micro-meters. Several biological transport 291 networks are also organised on the micro-scale; lymphatic capillaries ${ }^{93,94}$ have a 292 diameter of $\sim 10-60 \mu \mathrm{m}$, whilst circulatory vasculature ${ }^{95}$ measures on the order of 10 $293 \mathrm{~mm}$ in arteries and veins to around $1 \mu \mathrm{m}$ in capillaries. Micro-scale drug delivery

294 devices therefore offer the unique advantage of being able to interface with organoid,

295 cellular, and subcellular structures on a comparable length scale to their biological 296 targets. In addition, they may be able to navigate through the body's transport networks,

297 rendering them particularly suitable for localised and targeted delivery systems. Here, 298 we review a range of micro scale delivery systems with increasing target specificity.

\section{Systemic delivery systems}

Microfabricated electromechanical systems (MEMS)

301 Microfabrication techniques and advances in pump technology have allowed injection

302 and infusion devices (described earlier in the macro section) to be created on smaller

303 and smaller length scales. Micro fabricated electromechanical systems (MEMS) offer a

304 micron sized infusion device that can provide localised fixed rate or variable dose 
delivery, and recently further miniaturisation of fabrication technologies has encouraged

306 development of nanoelectromechanical systems ${ }^{96}$ (NEMS). MEMS systems can deliver

307 both liquid and solid-phase drug formulations ${ }^{97-104}$ in a manner analogous to macro

308 scale infusion pumps. The delivery dose is controlled by an infusion system, which is

309 either fixed rate (i.e. diffusion-based) or active (i.e. pumped) ${ }^{9,97}$. In pumped systems,

310 devices can be either non-mechanical (i.e. electrophoresis, electro osmosis) or

311 mechanical in nature (piezoelectric, electromagnetic, shape memory alloy), with the

312 choice of pump system impacting both the delivery dosage schedule and device life

313 time $\mathrm{e}^{101-103,105,106}$. For example, non-mechanical pumps usually have a limited flow rate

314 compared to variable piezoelectric pumps ${ }^{101,104,105,107-110}$ yet piezoelectric pump

315 systems often require higher voltage systems and increased operating power, reducing

316 battery and device lifetime. Although these devices are small enough to be implanted

317 within the body, they have a reduced reservoir capacity compared to their macro scale

318 counterparts. To combat the low loading capacity, refillable devices ${ }^{99}$ are being

319 developed which enable reservoir replenishment and dose manipulation post-

320 implantation. Due to the placement of these devices within the body, refilling these

321 systems will likely require an additional surgical procedure, rendering these devices

322 unsuitable for non-surgical applications.

\section{Microneedles}

324 Microneedle patches have been developed which facilitate drug delivery without

325 surgical intervention. These consist of an array of high aspect ratio needles ${ }^{90,91}$ on the

326 order of 500-1000 $\mu \mathrm{m}$ in length, which can penetrate the epidermis and reach the

327 underlying dermal layer. Once they are in contact with this layer, they can be used to

328 deliver small molecules, proteins, or nucleic acids via hollow, solid, or biodegradable

329 needles ${ }^{30}$. The needles are usually made of metal, silica, or polymer composites, and are 
330 fabricated through microlithography ${ }^{29,88-91,111}$ using etching, casting, or printing

331 methods. The simplest of these systems use solid and porous non-degradable needles

332 coated with a drug, or biodegradable drug-polymer composite that can dissolve into the

333 tissue once the microneedles contact the dermal layer. Alternatively, the microneedles

334 can be uncoated, and removed once they have penetrated the epidermal barrier,

335 allowing topical application of therapeutics to the area. An alternative system uses

336 hollow needles coupled to a liquid reservoir, using capillary action to inject liquid into

337 the dermal layer in an analogous manner to traditional macro needles. In contrast,

338 biodegradable needle systems can be applied directly to the skin and used to deliver

339 drugs with a more continuous release profile. By carefully tuning polymer

340 compositions, these systems can controllably deliver drugs in a single administration

341 lasting a few seconds, or with a longer kinetic release profile of a few weeks ${ }^{30,90}$.

\section{Polymer implants}

343 A range of injectable administration methods have been developed to implant polymer

344 based micro scaled drug delivery systems. The simplest of these involve micro scaled

345 polymer masses which are administered using a clinical gauge needle to directly

346 penetrate the skin barrier, and deposited subcutaneously. A wide range of injectable

347 polymer compositions have been explored, from early studies using polylactic acid and

348 biodegradable polylactide-co-glycolide acid polymer systems, to newer stimuli

349 responsive copolymer systems, and novel hydrogel systems ${ }^{112}$.

Micro scale injectable hydrogels with controlled release properties ${ }^{83,113-115}$ have emerged as promising polymer delivery systems for clinical applications. For example,

352 shear-thinning hydrogels are particularly well suited to subcutaneous systemic delivery

353 devices ${ }^{115-117}$, as they remain liquid during application and solidify on placement post- 
injection. This renders shear thinning hydrogel systems suitable for delivery to a wide range of target locations, however for longer term release profiles (over 6 months) multiple hydrogel injections would likely be required in a clinical setting. To prevent overloading the subcutaneous space with polymer materials, hydrogels with tuneable degradation rates (matched to the rate of drug release) can ensure polymer residue does not remain in the body after the therapeutic has been delivered. As an alternative,

360 refillable drug delivery depots have recently been developed, which aim to overcome 361 the drug loading limitations inherent in microscopic drug delivery depots. These systems use "tagged" drugs which can be administered intravenously and migrate towards the polymer depot ${ }^{118,119}$, providing a refillable controlled release depot.

\section{Microparticles}

Microparticles typically consist of a degradable, drug loaded microparticle that acts as a drug delivery depot. These particles can be suspended in saline, and injected intravenously where, if appropriately sized, they circulate systemically. Microparticles are typically formed by emulsion or solvent evaporation techniques ${ }^{15,32,120-125}$, potentially resulting in a loss of potency for sensitive therapeutics after exposure to organic solvents during the fabrication method. In an alternative approach, ultrasonication and freezing can be used to generate microparticles with control over polydispersity[11], reducing the need for organic solvents and maintaining drug potency. A variety of polymers have been used to fabricate microparticles, and the

374 choice of polymer directly impacts both the microparticle targeting ability and the specific release kinetics. For example, PLGA microparticles are FDA approved for clinical use in a range of applications, including chemotherapeutic drug delivery and hormone release. Their release profiles can be tuned to continuously deliver therapeutic

378 load over the course of two days, or for up to eight weeks, depending on the lactide to 
379 glycolide ratio ${ }^{126-128}$ within the polymer. Recently, more advanced microparticles have

380 been developed which offer a more complex kinetic release profile. These materials

381 combine several different polymer architectures to offer a single particle that can release

382 therapeutic load in 2-3 distinct bursts. These systems are likely to prove extremely

383 useful in vaccine development, where an entire multi-dose vaccination schedule could

384 be administered systemically in one injection ${ }^{11,129}$.

\section{Localised delivery systems}

\section{Implantable microchips}

387 As infusion pump and microchip devices have been miniaturised, they have become

388 increasingly suitable for localised drug delivery applications. Recently, new MEMS

389 devices have been developed which offer an implantable "pharmacy-on-a-chip" design,

390 allowing the delivery of multiple therapeutics, each at a specified time. These devices

391 can provide precise dosing control through as many as 100 unique reservoirs opened on

392 the order of microseconds. The first "pharmacy-on-a-chip" devices successfully

393 completed phase one human clinical trials in 2012, and were used to deliver human

394 parathyroid hormone fragment ${ }^{86,130}$ to eight osteoporotic patients. Taking this

395 technology further, micron-sized reservoir-based devices holding up to 100 drugs and

396 drug combinations in a small microchip have been implanted into tumour sites. Due to

397 their high aspect ratio and small scale, implants can be extracted using a conventional

398 biopsy needle, and the tissue can be examined to determine tumour regression in

399 response to each of the therapeutic drugs and drug combinations tested. In this way,

400 surgeons and oncologists can develop a personalised drug treatment plan for cancer

401 patients based on positive responses to specific drug combination therapies ${ }^{131}{ }^{132}$, tested using the microchip. 
404 Polymers can be modified to display controlled topographical and physical features,

405 enabling delivery of therapeutics to a specific biological target organ. For example, the

406 Nektar aerosolised inhaler based systems deliver microparticles containing a range of

407 therapeutics, and uses microparticles with a reduced density to aid pulmonary particle

408 delivery ${ }^{133}$. Microparticle geometry has also been shown to directly impact cellular

409 uptake, with both particle size and shape ${ }^{134-138}$ playing an important role in the response

410 of specific tissues and cells. Given the importance of the three dimensional structure to

411 cellular interactions, shape memory polymers are being developed that can be injected

412 into a target organ using a syringe, and then resume a specific $2 \mathrm{D}$ or $3 \mathrm{D}$ shape on

413 reaching $37^{\circ} \mathrm{C}$ in the body. One example of these systems involves bio-adhesive shape

414 memory hydrogel sheets, which provide an easily applied, injectable patch drug

415 delivery device for local drug administration ${ }^{72,139-142}$.

\section{Targeted delivery systems}

\section{Ligand targeting}

418 The identification of organ and cell specific ligands has facilitated targeted delivery of

419 micro scale systems. This is often accomplished using conjugation strategies which link

420 targeting ligands onto polymers. Ligand conjugated polymers can be used to form drug

421 delivery microparticles, which can be formulated to encapsulate a range of therapeutic

422 cargo including proteins, small molecules, and cytokines within a ligand decorated

423 polymer shell ${ }^{17,143}$. Conjugation of specific ligands can also alter the systemic

424 circulation time; for example the inclusion of a polyethylene glycol (PEG) moiety is

425 thought to prevent binding and uptake of microparticles by non-targeted cell types. The

426 inclusion of specific ligands facilitates microparticle binding to specific cells and tissues 
presenting the receptor for the attached ligand. These systems have proven particularly

428 useful for targeting the liver though the ASGPR1 receptor ${ }^{144,145}$, or targeting systemically circulating dendritic cells ${ }^{146,147}$. As ligands of other target organs are identified, this method will enable more specific targeting.

432 In an alternative approach, smaller, drug loaded microbubbles have been injected

433 systemically. The application of ultrasound (which bursts these bubbles) can be used to 434 target drug release to a specific therapeutic area. This emerging technology makes use 435 of clinically available imaging facilities located in hospitals and clinics to induce 436 controlled release in target biological structures. The technique has proven popular in 437 delivering drugs to larger target organs, such as the kidney ${ }^{148-150}$. The development of 438 ultrasound mediated drug deliver follows previous discoveries that traditional delivery 439 through topical administration to the skin, gastrointestinal tract and mucus membranes 440 is enhanced with simultaneous application of an ultrasound probe $\mathrm{e}^{151,152}$.

\section{$441 \quad$ Summary}

442 Micro scale systems offer a robust tool to facilitate drug delivery in systemic, localised,

443 and targeted fashions. Whilst macro scale devices can offer controlled release for

444 durations of months to years, micro systems have limited reservoir and loading

445 capacity, usually limiting drug delivery to weeks and months. There are also limited

446 examples of systems with programmed release profiles, as the majority of the drug

447 delivery systems rely on diffusion and biodegradation to provide a continuous and fixed 448 rate delivery. Recently, pulsatile hydrogel release systems, pulsatile microparticles, and

449 stimuli responsive drug delivery approaches have been developed which offer the 450 promise of greater control over complex dosing schedules. Although micro systems are 
451 limited by therapeutic reservoir and release profiles, they excel in providing localised

452 and targeted drug delivery. Their small scale enables implantation into key organs, and

453 microparticles and microbubbles can travel through the vasculature to enable both

454 systemic and more targeted delivery. Poorly vascularised tissues, and those isolated by

455 complex physiological barriers such as the blood-brain barrier, remain difficult to target.

456 As new approaches to crossing physiological barriers are identified, micro scale systems

457 will play an increasingly important role in targeted delivery.

\section{NANO SCALE DELIVERY SYSTEMS}

Nanoscale systems are generally defined as being of the order of between 1 to

$460100 \mathrm{~nm}$ (ISO/TS 80004-1:2015), however in practice can range from 1 to $1000 \mathrm{~nm}^{153}$.

461 Nanotechnology can be used to improve the pharmacokinetic properties of traditional

462 pharmaceuticals, increase circulation time, solubility, and enhance delivery into

463 difficult-to-access tissues. In addition, nanostructures below $200 \mathrm{~nm}$ can undergo

464 uptake in various cell types and avoid clearance by phagocytosis ${ }^{154}$, making nanoscale

465 systems particularly promising for targeted intra-cellular delivery of a variety of

466 therapeutic cargo. This section will provide an overview of recent advances in

467 nanotechnology for drug delivery, and identify remaining challenges.

\section{Systemic delivery systems}

\section{$469 \quad$ Nanoparticles}

470 Nanoparticle systems enable the systemic delivery of sensitive or unstable therapeutics

471 by protecting them against degradation, extending circulation time, and facilitating

472 delivery across biological barriers that would normally be prevented due to

473 hydrophilicity, size or charge [9, 10]. Re-formulating existing drugs into nanoparticle 
delivery systems can reduce toxicity, and nanoparticles can be formulated using a

475 variety of materials including lipids, polymers and peptides. Nanoparticle formulations can also be used to deliver sensitive cargo at risk of degradation from ubiquitous nucleases in vivo, such as nucleic acids. Systemic nanoparticle mediated delivery has been demonstrated for mRNA ${ }^{155}$, and localized delivery of DNA has been demonstrated following topical application of DNA nanoparticles to the $\operatorname{skin}^{156}$ in patients with 480 epidermolysis bullosa.

481 To improve solubility, drugs are often encapsulated inside micelle carriers, or conjugated to water soluble polymers. Liposome-based carriers were first described in the 1960s and are amongst the most well established nano-carriers for systemic delivery 157. They have been widely used to improve aqueous solubility of hydrophobic drugs, illustrated by the antifungal amphotericin $\mathrm{B}$, which is insoluble at physiological $\mathrm{pH}$ and also highly toxic. The liposomal formulation of this drug, AmBisome®, can be administered systemically with dramatically reduced toxicity ${ }^{158-160}$.

Synthetic conjugates have also been used to formulate drug delivery nanoparticles, and inclusion of water soluble polymers, such as polyethylene glycol, can aid systemic solubility without the inclusion of dose-limiting solvents. Paclitaxel is an example of a poorly water-soluble drug that has been formulated within degradable polylactidepolyethylene glycol block co-polymers, allowing better delivery through nanoscale drug delivery micelles (Genexol-PM). These micellar nanoparticle formulations can also enhance transdermal drug delivery ${ }^{161-163}$, and have been used to deliver hormones such as estradiol via topical application. The incorporation of polyethylene glycol (PEG) into these nanoparticle systems can increase particle stability ${ }^{164-166}$, reduce protein

497 adsorption (opsonization), and prevent subsequent phagocytic clearance. For example, PEGylated liposomal doxorubicin formulations have been shown to extend circulation 
499 times ${ }^{164,167}$ when compared to uncoated liposomes, or free doxorubicin. However,

500 studies have indicated that repeated administration of PEGylated formulations can lead

501 to an increased clearance rate of subsequent doses of PEGylated liposomes. This is

502 likely due to IgM antibodies raised after first exposure ${ }^{164}$ or pre-existing IgG antibodies

503 to PEG. ${ }^{168}$

\section{$504 \quad$ Nanowires, nanoneedles and nanotubes}

505 High-aspect-ratio nanoscale systems ${ }^{169-171}$ such as nanowires, nanoneedles and

506 nanotubes have been used to deliver a wide variety of biomolecules, and can be

507 combined with macro and micro systems to enhance drug delivery technologies. For

508 example, micron scaled drug delivery particles have been coated with nanowires which

509 enhance retention in the mucosal tract. This strategy enables prolonged retention to

510 mucosal epithelial tissue ${ }^{172}$, facilitating enhanced drug delivery and limiting clearance.

511 In addition, nano scale needles (nanoneedles), wires, and tubes can be loaded directly

512 with drugs for intracellular drug delivery. Biodegradable silicon nanoneedles grafted

513 onto micron sized patches have been used for the intra-cellular delivery of VEGF DNA

514 to localised regions of skin and exposed muscle ${ }^{169}$, where they are able to enhance

515 neovascularization compared to delivery of naked DNA. Recently, more sophisticated

516 systems have been developed which can release cargo in response to specific stimuli ${ }^{29}$,

$517{ }^{92}$, including changes in $\mathrm{pH}$ and temperature, and the presence of specific enzymes.

518 High-aspect delivery systems are typically silicon-based, however alternative materials

519 (such as carbon nanotube based drug reservoirs ${ }^{173-176}$ ) are currently being developed.

520 These material systems will need to meet stringent nano scale safety and toxicity

521 requirements before widespread clinical use. 
523 Nanoscale hydrogels (nanogels) broadly consist of crosslinked polymeric particles

524 which can be synthesized using a range of synthetic and naturally derived materials including polyacrylamides, polydimethylsiloxane, and chitosan ${ }^{166,177-180}$. Nanogels offer

526 a large surface area for bioconjugation, and as for the microgel systems described

527 earlier, cross-linking can be used to fine tune drug delivery release kinetics for the

528 delivery of hydrophobic, hydrophilic and charged solutes. Nanogels have been used for

529 both targeted intracellular delivery and systemic delivery. These systems have recently

530 been applied to intra-nasal vaccine delivery, where they can be retained in nasal mucosa

531 to generate systemic immunity as well as local mucosal immunity ${ }^{181,182}$.

\section{Localised delivery systems}

Stimuli responsive nanosystems

534 In an effort to move towards systems with spatio-temporal control of drug delivery, a number of nanosystems have been developed which can be triggered to release cargo by exposure to external stimuli such as heat, light and ultrasound. Ultrasound has been utilized to increase transdermal delivery of a variety of nanoparticles through the $\operatorname{skin}^{29}$, ${ }^{149,150}$, whilst heat and light sensitive nanosystems have enabled delivery to deeper tissues. For example, thermosensitive lipids that have transition temperatures between $40-45^{\circ} \mathrm{C}$ can be used to formulate liposomes that become unstable and release cargo

541 once exposed to this temperature. ThermoDox ${ }^{\circledR}$ is a temperature-sensitive doxorubicin-

542 PEGylated liposome that is systemically delivered but releases cargo in regions where

543 local temperatures are elevated to $40{ }^{\circ} \mathrm{C}$ by application of radiofrequency. The thermo-

544 responsive formulation was shown to increase local concentration of the drug several folds higher in the radiofrequency treatment area compared to intravenously 
546 administered doxorubicin, and compared to non-thermosensitive liposomal formulations

547 of doxorubicin ${ }^{183}$.

$548 \quad$ Alternatively, light has been used as an external stimulus for photodynamic

549 therapies. Visudyne ${ }^{\circledR}$ is a liposomal formulation of verteporfin ${ }^{184,185}$ used to treat

550 ocular conditions. It is systemically administered but only exerts its toxic effects when

551 exposed to light. When light is applied to the eye, this formulation can be used to treat

552 ocular neovascularization due to diseases such as age-related macular degeneration. For

553 these treatments to be successful, stimuli must be able to penetrate to the target tissue to

554 facilitate drug release. This renders tissues closer to the surface more amenable to these

555 therapies; for deeper structures alternative targeted delivery systems are required.

\section{$556 \quad$ Targeted delivery systems}

\section{Site-specific accumulation}

558 Systemically delivered nanoparticle systems may accumulate in organs such as the

559 liver, lung and in tumors. This site-specific accumulation after systemic administration

560 has been observed using nanocarriers where there is no specific targeting moiety.

561 Nanoparticles that tend to accumulate at tumor sites are thought to be subject to the

562 enhanced permeability and retention ${ }^{186}$ (EPR) effect. Nanoparticles are small enough to

563 traverse through the leaky blood-tumor barrier resulting in accumulation and therefore

564 enhanced drug delivery to the tumor site. Lung accumulation is thought to be due to the

565 cationic nature of nanoparticles leading blood component aggregation and accumulation

566 in pulmonary vasculature. ${ }^{187,188}$

567 Selective biodistribution has also been attributed to in vivo post-modification of

568 nanoparticles, where particular apolipoproteins are preferentially adsorbed onto the

569 nanoparticle, and can facilitate trafficking to, and enhance retention in, the 
corresponding organ. In one example, polysorbate 80 modified polybutylcyanoacrylate nanoparticles were used to deliver doxorubicin to the brain. Doxorubicin does not cross the blood brain barrier alone, but when delivered as a nanoparticle formulation, delivery to the brain was achieved ${ }^{189}$ and found to be due to adsorption of apolipoprotein onto

574 the polymer nanoparticles. Similarly, lipid nanoparticles carrying nucleic acids were

575 shown to accumulate in the liver after adsorption of apolipoprotein $\mathrm{E}^{190,191}$. These

576 examples demonstrate that nanoparticle design must consider factors such as particle size, charge and shape ${ }^{170,192}$, which can influence tissue accumulation and therefore targeting efficacy.

\section{Receptor-mediated targeting}

In a similar manner to microparticle based delivery, nanoparticles can be formulated with protein and ligand tags to enable selective delivery. Identifying specific receptor ligand pairs which enable cell selective delivery is a topic of great interest. To reduce phagocytosis and enhance therapeutic efficacy, nanosystems can be conjugated with “self" peptides such as CD47 ${ }^{193}$ which act as a “don't eat me" marker. For tumor targeting, nanoparticles can be decorated with ligands that target receptors that are overexpressed in cancer cells, such as the transferrin receptor ${ }^{194}$. Protein and antibody tagging can also facilitate organ and cellular targeting; HER2 antibodies have been conjugated to liposomal doxorubicin ${ }^{165}$ to mediate targeted binding in breast cancer.

589 Antibody presentation on nanoparticles can also increase cellular particle uptake; when trastuzumab and rituximab were bound to PLA particles, particle uptake was increased six-fold compared with PLA particles lacking targeting molecules ${ }^{195}$. In an alternative

592 strategy, Abraxane, an albumin bound nanoparticle formulation of paclitaxel, is thought 593 to undergo an albumin-receptor (gp60) mediated endothelial transcytosis ${ }^{196-198}$, enabling the drug to pass through endothelial cell walls in tumor micro vessels to achieve 
enhanced intra-tumoral concentrations and anti-tumor activity.

596 In addition to targeting specific cells, nanocarriers that contain cargo must also

597 efficiently enter cells to deliver the therapeutic component. Particle shape, size, and 598 composition can all affect penetration efficacy, and coating the nanoparticle with cell

599 penetrating peptides is proving a promising strategy. By screening a library of cell

600 penetrating peptides (CPP) using a high throughput strategy, three human peptides were

601 identified which improved in vivo delivery when conjugated to lipid-like

602 nanoparticles ${ }^{199}$. As the mechanism for cellular entry and endosomal escape become

603 better understood, new ligands will be identified to enhance these processes and

604 enhance intracellular targeting with increased specificity and efficiency.

\section{Summary}

606 Nano based systems are an enabling technology for the delivery of traditional drugs and

607 novel therapies such as nucleic acid based drugs. Nanoparticles can be used to optimize

608 the pharmacokinetics of conventional therapeutics, and offer a promising platform for

609 targeting specific cells and organelles by manipulating biological pathways such as

610 endocytosis and ligand targeting to gain cellular entry. Due to their small scale, drug

611 loading and precision engineering is challenging, rendering current nanoscale systems

612 less suited for the continued or controlled release of therapeutic loads. Additionally, the

613 development of safe and effective nanoscale materials presents a significant hurdle for

614 clinical translation.

\section{CONCLUSIONS}

616 Modern drug therapies include small molecules, proteins, and genetic

617 engineering based strategies. These therapies often have precise biological therapeutic

618 targets, and are most effective when delivered with specific dosing regimens. The need 
619 to combine targeted delivery and dosing in smaller and smaller scale systems has driven

620 the miniaturisation of drug delivery devices from the macro to micro to the nano scale.

621 We have reviewed a range of devices and described their ability to controllably deliver

622 biomolecules, summarised in Table 1 and Figure 4. In general, macro devices offer

623 precisely engineered systems which can provide systemic and localised drug delivery

624 over a period of several years. Devices have a defined lifetime, usually limited by

625 battery power and reservoir capacity, before they need to be surgically replaced. In

626 some cases, precision engineering and the incorporation of wireless sensors for on-

627 demand sensing has enabled patient specific drug delivery, most commonly applied to

628 insulin therapies. As the length scale of these devices is reduced to smaller macro

629 devices, they can be surgically implanted into additional target organs to enable

630 localised therapeutic delivery, however their scale limits their ability to target smaller

631 biological structures. In a smart workaround, cell specific delivery can be achieved

632 using macro scale polymer implants that recruit desired cells for targeted delivery, and

633 when coupled with refillable drug depots this will provide an exciting future direction

634 for cell specific delivery.

635 In contrast, micro and nano systems can often be coupled with targeting ligands and can

636 travel through the vasculature and lymphatic systems to reach specific cell targets.

637 Several of these systems can undergo burst release in response to external stimuli such

638 as light, heat, or ultrasound. However, there are limited examples of these systems being

639 able to intrinsically facilitate controlled dosing schedules. Notable exceptions are burst

640 release polymer particles which offer a single administration of an entire dosing

641 schedule, and stimuli responsive nanoneedle delivery systems which use cleavable

642 linkers to deliver therapeutics in response to target enzyme expression. These systems

643 straddle the boundary between sensing and drug delivery and offer an exciting direction 
644 for responsive drug delivery therapies. A major limitation to micro and nano scale

645 systems is the limited therapeutic load these systems can carry, limiting the duration of

646 controlled release to between hours and, at most, a few months. This suggests micro-

647 and nano- scale systems are best suited to short term delivery of up to 3 months, or the

648 targeted delivery of curative and preventative therapeutics that can be administered with

649 a single application.

650 Moving forwards, next generation devices will focus on increasing the efficacy of

651 therapeutic delivery at smaller and smaller length scales. As mechanisms of

652 nanoparticle cellular entry and endosomal escape are elucidated, nanoscale systems with

653 greater delivery efficacy and therapeutic effect will be developed. Additionally, the

654 development of stimuli responsive polymer systems will enable on-demand and patient-

655 specific delivery systems to be developed in response to specific cues. Future devices

656 will combine the advantages of macro scale delivery systems with the precise targeting

657 capabilities of devices on the nano scale.

658 
FIGURES AND TABLES:

660 FIGURE 1: Length scales in drug delivery An overview of the biological length

661 scales important in drug delivery, including target organs, biological barriers and sub-

662 cellular structure of interest.

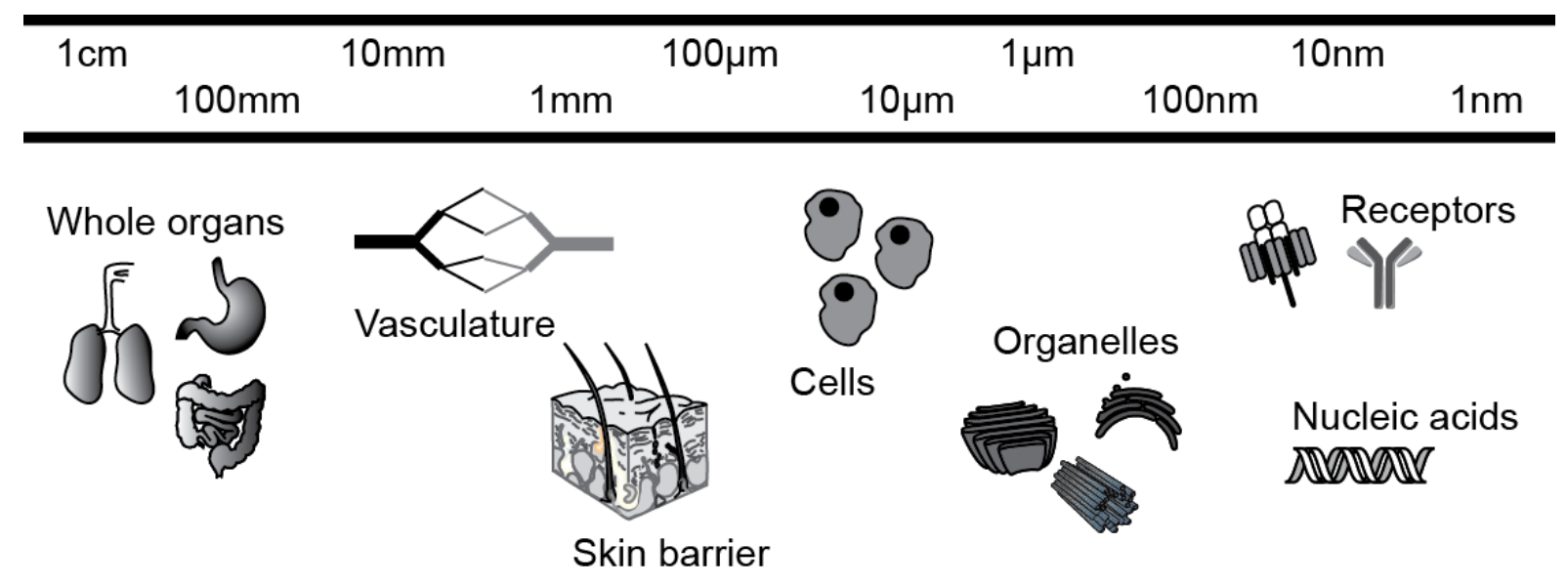

664 
665 FIGURE 2: Miniaturisation of controlled dosing pump systems Infusion based

666 devices have progressed rapidly from macroscale implantable pump systems able to

667 deliver single therapeutics (A) to micro scaled pumps capable of delivering over 100

668 individual doses (B). Figures were adapted from the following references with

669 permission: A- Adapted with permission from Nature Biotechnology ${ }^{200}$ @ 2003; B-

670 Reprinted with permission from Science Translational Medicine ${ }^{130}$ @ 2012.

Minaturisation

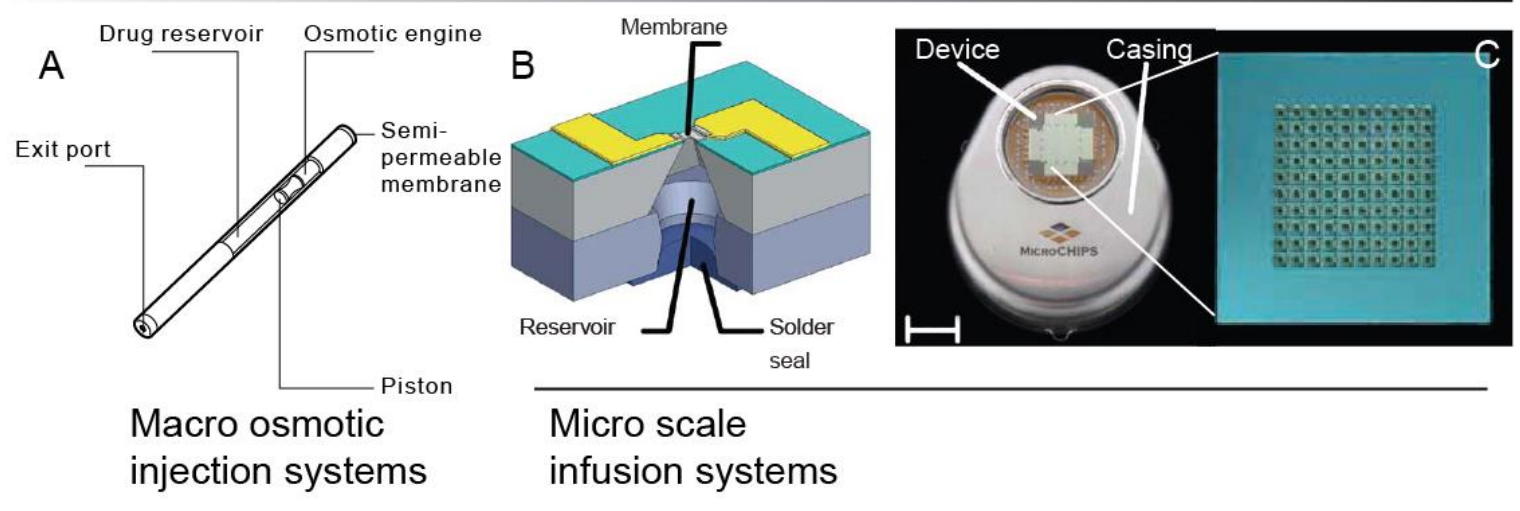

672 
674 based drug delivery systems offer extremely versatile morphologies for drug delivery

675 applications across several orders of magnitude. On the macro scale, flexible polymers

676 have been folded into capsules small enough to swallow. (A) Precision engineering has

677 enabled macro scale stents which possess micron scale features. These features are often

678 made of, or coated in, biodegradable polymer substrates (B) providing both rigidity and

679 drug eluting capabilities. (C) Polymer nanoneedles can be fabricated with a variety of

680 aspect ratios to penetrate cells for nucleic acid drug delivery. Figures were adapted

681 from the following references with permission: A- Reprinted with permission from

682 Science Translational Medicine 201 C 2016. B- Reprinted with permission from the

683 Journal of Interventional Cardiology ${ }^{202}$ @ 2004. C- Reprinted by permission from

684 Macmillan Publishers Ltd [165] @ 2015.

685

Macro scale
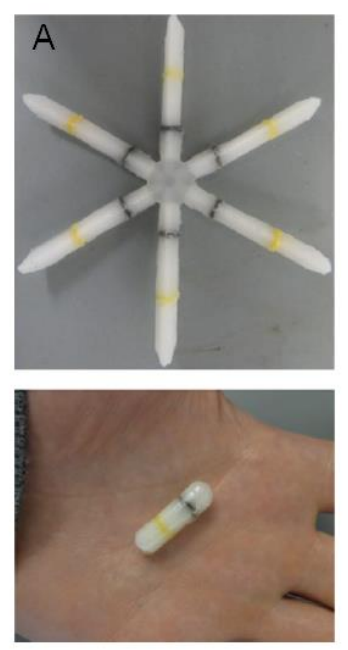

Micro scale
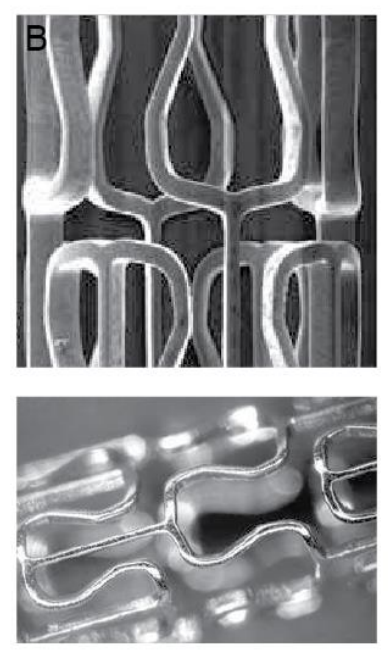

Nano scale
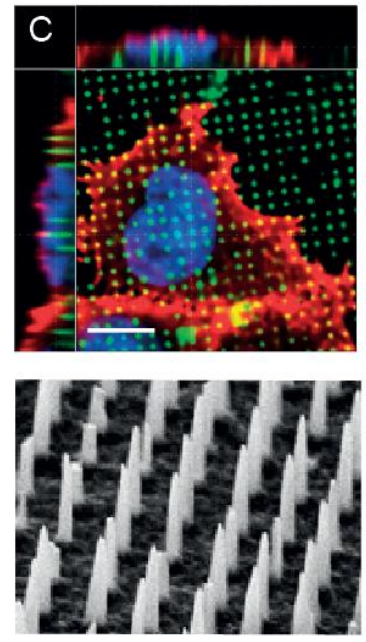

Delivery duration 
688 between drug delivery strategies across length scales, illustrated by material delivery

689 class, scale and the targeting ability to each therapy. Due to their scale, there are few

690 examples of targeted macro scale drug delivery systems.

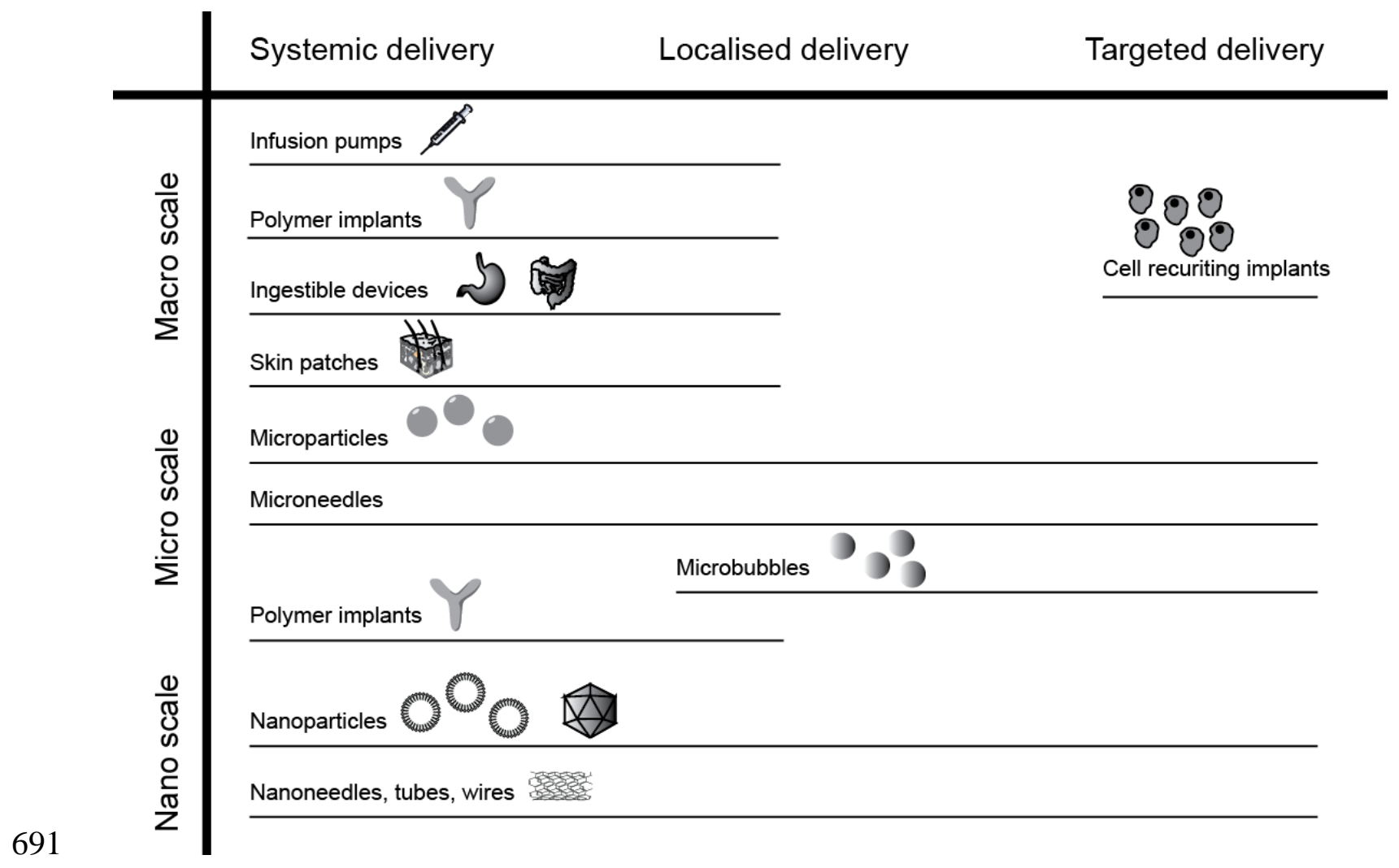


TABLE 1: Considerations in drug delivery device design The table provides an

693 extension to Figure 4, and overview of the main considerations in drug delivery device

694 design according to device scale. Types of device, typical therapeutics, targeting ability

695 and typical delivery profiles are indicated for highlighted delivery systems.

\begin{tabular}{|c|c|c|c|c|c|c|c|c|c|c|c|}
\hline \multirow[t]{2}{*}{ Scale } & \multirow{2}{*}{$\begin{array}{l}\text { Device } \\
\text { (administration route) }\end{array}$} & \multirow{2}{*}{$\begin{array}{l}\text { Types of therapeutic } \\
\text { typically delivered }\end{array}$} & \multicolumn{3}{|c|}{ Targeting } & \multicolumn{6}{|c|}{ Delivery Duration } \\
\hline & & & 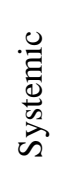 & 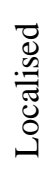 & 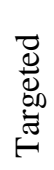 & $\begin{array}{l}\stackrel{n}{\Xi} \\
\stackrel{0}{O}\end{array}$ & $\hat{\beth}_{\tilde{\theta}}^{\infty}$ & $\begin{array}{l}\frac{n}{d} \\
3 \\
3\end{array}$ & 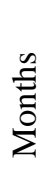 & $\begin{array}{l}+ \\
0 \\
\stackrel{\Xi}{\Xi} \\
0 \\
\Xi \\
0\end{array}$ & 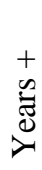 \\
\hline \multirow[t]{4}{*}{ Macro } & $\begin{array}{l}\text { Ingestible devices } \\
\text { (ingestion) }\end{array}$ & $\begin{array}{l}\text { Peptides, Proteins, Small } \\
\text { molecules }\end{array}$ & & & & & & & & & \\
\hline & Skin patches & $\begin{array}{l}\text { Peptides, Proteins, small } \\
\text { molecules }\end{array}$ & & & & & & & & & \\
\hline & Polymer implants & $\begin{array}{l}\text { Peptides, Proteins, Small } \\
\text { Molecules }\end{array}$ & & & & & & & & & \\
\hline & Pumps & Proteins, Small Molecules & & & & & & & & & \\
\hline \multirow[t]{4}{*}{ Micro } & Microneedles & $\begin{array}{l}\text { Peptides, Proteins, Small } \\
\text { Molecules, nucleic acids }\end{array}$ & & & & & & & & & \\
\hline & Microparticles & Proteins, Small Molecules & & & & & & & & & \\
\hline & Polymer implants & Proteins, Small Molecules & & & & & & & & & \\
\hline & Microbubbles & Proteins & & & & & & & & & \\
\hline \multirow[t]{3}{*}{ Nano } & $\begin{array}{l}\text { Nanoneedles, tubes and } \\
\text { wires }\end{array}$ & $\begin{array}{l}\text { Peptides, Proteins, nucleic } \\
\text { acids, small molecules }\end{array}$ & & & & & & & & & \\
\hline & Nanogels & $\begin{array}{l}\text { Peptides, proteins, small } \\
\text { molecules }\end{array}$ & & & & & & & & & \\
\hline & Nanoparticles & $\begin{array}{l}\text { Peptides, Proteins, nucleic } \\
\text { acids, small molecules, } \\
\text { nucleic acids }\end{array}$ & & & & & & & & & \\
\hline
\end{tabular}


699 A.K.P and D.D gratefully acknowledge the Engineering and Physical Sciences Research

700 Council (EPSRC) for the Engineering, Tissue Engineering and Regenerative Medicine

701 (E-TERM) award (EP/I017801/1).

702

703 DECLARATIONS OF INTEREST

704 R.L. is co-inventor on multiple patents and patent applications describing drug delivery

705 systems, and has a financial interest in Lyndra Inc., a biotechnology company focused

706 on the development of oral drug delivery for long drug release. The rest of the authors

707 declare no competing financial interests.

708

\section{REFERENCES}

710 1. Newman, D. J.; Cragg, G. M. Journal of Natural Products 2007, 70, (3), 461.

$711 \quad 2 . \quad$ Muralidhara, B. K.; Baid, R.; Bishop, S. M.; Huang, M.; Wang, W.; Nema, S. Drug

712 Discovery Today 2016, 21, (3), 430.

713 3. Sharma, C.; Awasthi, S. K. Chemical Biology \& Drug Design 2017, 89, (1), 16.

714 4. Kimchi-Sarfaty, C.; Schiller, T.; Hamasaki-Katagiri, N.; Khan, M. A.; Yanover, C.;

715 Sauna, Z. E. Trends in Pharmacological Sciences 2013, 34, (10), 534.

$716 \quad 5 . \quad$ Eckstein, P. British Medical Bulletin 1970, 26, (1), 52.

$717 \quad 6 . \quad$ Sutradhar, K. B.; Sumi, C. D. Drug Deliv. 2016, 23, (1), 1.

7187 7. Fox, C. B.; Kim, J.; Le, L. V.; Nemeth, C. L.; Chirra, H. D.; Desai, T. A. Journal of

719 Controlled Release 2015, 219, 431.

720 8. Goffredo, R.; Accoto, D.; Guglielmelli, E. Expert Review of Medical Devices 2015, 12, 721 (5), 585.

722 9. Grayson, A. C. R.; Choi, I. S.; Tyler, B. M.; Wang, P. P.; Brem, H.; Cima, M. J.;

723 Langer, R. Nature materials 2003, 2, (11), 767.

724 10. Kearney, C. J.; Mooney, D. J. Nature materials 2013, 12, (11), 1004.

725 11. McHugh, K. J.; Guarecuco, R.; Langer, R.; Jaklenec, A. Journal of Controlled Release $726 \mathbf{2 0 1 5}, 219,596$.

727 12. Franzesi, G. T.; Ni, B.; Ling, Y. B.; Khademhosseini, A. J. Am. Chem. Soc. 2006, 128, 728 (47), 15064.

729 13. Ganji, F.; Vasheghani-Farahani, E. Iranian Polymer Journal 2009, 18, (1), 63.

$730 \quad$ 14. Reeves, A. R. D.; Spiller, K. L.; Freytes, D. O.; Vunjak-Novakovic, G.; Kaplan, D. L.

731 Biomaterials 2015, 73, 272.

732 15. Rodriguez Villanueva, J.; Bravo-Osuna, I.; Herrero-Vanrell, R.; Molina Martinez, I. T.;

733 Guzman Navarro, M. European Journal of Pharmaceutical Sciences 2016, 92, 287.

734 16. Guo, X.; Cui, F.; Xing, Y.; Mei, Q.; Zhang, Z. Pharmazie 2011, 66, (12), 948.

735 17. Simon-Yarza, T.; Formiga, F. R.; Tamayo, E.; Pelacho, B.; Prosper, F.; Blanco-Prieto,

736 M. J. International Journal of Pharmaceutics 2013, 440, (1), 13.

737 18. Deng, Y. H.; Wang, C. C.; Shen, X. Z.; Yang, W. L.; An, L.; Gao, H.; Fu, S. K. Chem.-

738 Eur. J. 2005, 11, (20), 6006. 
19. Li, H.; Go, G.; Ko, S. Y.; Park, J. O.; Park, S. Smart Mater. Struct. 2016, 25, (2), 9.

20. Wanakule, P.; Liu, G. W.; Fleury, A. T.; Roy, K. Journal of Controlled Release 2012, $162,(2), 429$.

21. White, E. M.; Yatvin, J.; Grubbs, J. B.; Bilbrey, J. A.; Locklin, J. Journal of Polymer Science Part B-Polymer Physics 2013, 51, (14), 1084. 22. Zorzetto, L.; Brambilla, P.; Marcello, E.; Bloise, N.; De Gregori, M.; Cobianchi, L.; Peloso, A.; Allegri, M.; Visai, L.; Petrini, P. International Journal of Nanomedicine 2016, 11, 2695. 23. Blackshear, P. J.; Rohde, T. D.; Prosl, F.; Buchwald, H. Medical Progress through Technology 1979, 6, (4), 149.

749 24. Theeuwes, F.; Yum, S. I. Annals of Biomedical Engineering 1976, 4, (4), 343. Schaefer, U. F.; Lehr, C. M. European Journal of Pharmaceutics and Biopharmaceutics 2013, 84, (2), 239.

26. Avery, M.; Liu, D. Food and Drug Law Journal 2011, 66, (3), 329.

27. van der Schaar, P. J.; Dijksman, F.; Shimizu, J.; Wanke, C.; Siersema, P. D. Gastroenterology 2011, 140, (5), S766.

28. van der Schaar, P. J.; Dijksman, J. F.; Broekhuizen-de Gast, H.; Shimizu, J.; van Lelyveld, N.; Zou, H.; Iordanov, V.; Wanke, C.; Siersema, P. D. Gastrointestinal Endoscopy 2013, 78, (3), 520.

29. Barry, B. W. European Journal of Pharmaceutical Sciences 2001, 14, (2), 101. 30. Caffarel-Salvador, E.; Donnelly, R. F. Current Pharmaceutical Design 2016, 22, (9), 1105 .

31. Garg, N. K.; Singh, B.; Tyagi, R. K.; Sharma, G.; Katare, O. P. Colloid Surf. BBiointerfaces 2016, 147, 17.

32. Park, C. H.; Tijing, L. D.; Kim, C. S.; Lee, K.-M. Colloid Surf. B-Biointerfaces 2014, 123,710 .

33. Singh, B. N.; Kim, K. H. Journal of Controlled Release 2000, 63, (3), 235.

34. Rujivipat, S.; Bodmeier, R. European Journal of Pharmaceutics and Biopharmaceutics 2010, 76, (3), 486.

35. Zhang, S. Y.; Bellinger, A. M.; Glettig, D. L.; Barman, R.; Lee, Y. A. L.; Zhu, J. H.; Cleveland, C.; Montgomery, V. A.; Gu, L.; Nash, L. D.; Maitland, D. J.; Langer, R.; Traverso, G. Nature materials 2015, 14, (10), 1065.

36. Dahlgren, D.; Roos, C.; Lundqvist, A.; Abrahamsson, B.; Tannergren, C.; Hellstrom, P. M.; Sjogren, E.; Lennernas, H. Molecular Pharmaceutics 2016, 13, (9), 3013.

37. Prausnitz, M. R.; Langer, R. Nat Biotechnol 2008, 26, (11), 1261.

38. Chetkowski, R. J.; Meldrum, D. R.; Steingold, K. A.; Randle, D.; Lu, J. K.; Eggena, P.; Hershman, J. M.; Alkjaersig, N. K.; Fletcher, A. P.; Judd, H. L. New England Journal of Medicine 1986, 314, (25), 1615.

39. Davis, S. R.; Dinatale, I.; Rivera-Woll, L.; Davison, S. Journal of Endocrinology 2005, 185, (2), 207.

40. Prausnitz, M. R.; Mitragotri, S.; Langer, R. Nature Reviews Drug Discovery 2004, 3 , (2), 115.

41. Wadgave, U.; Nagesh, L. International Journal of Health Sciences-Ijhs 2016, 10, (3), 425.

42. Polaneczky, M.; Slap, G.; Forke, C.; Rappaport, A.; Sondheimer, S. New England Journal of Medicine 1994, 331, (18), 1201.

43. Shoupe, D.; Mishell, D. R. American Journal of Obstetrics and Gynecology 1989, 160, (5), 1286.

44. $\quad$ Sivin, I. Studies in Family Planning 1988, 19, (2), 81.

45. Brem, H.; Mahaley, S.; Vick, N. A.; Black, K. L.; Schold, S. C.; Burger, P. C.; Friedman, A. H.; Ciric, I. S.; Eller, T. W.; Cozzens, J. W.; Kenealy, J. N. Journal of Neurosurgery 1991, 74, (3), 441.

46. $\quad$ Chew, S. A.; Danti, S. Advanced Healthcare Materials 2017, 6, (2), 22. 

Journal of Antimicrobial Chemotherapy 2003, 51, (3), 585. 48. Lee, S. S.; Hughes, P.; Ross, A. D.; Robinson, M. R. Pharmaceutical Research 2010, 27, (10), 2043.

49. Ochoa, M.; Mousoulis, C.; Ziaie, B. Advanced Drug Delivery Reviews 2012, 64, (14), 1603.

50. Abolmaali, S. S.; Tamaddon, A. M.; Dinarvand, R. Journal of Nanoparticle Research 2013, 15, (12).

51. Calo, E.; Khutoryanskiy, V. V. European Polymer Journal 2015, 65, 252.

52. Bory, C.; Lege, P.; Chalencon, E.; Milano, S. Journal of Pharmacological and Toxicological Methods 2014, 70, (3), 349.

53. Tan, T.; Watts, S. W.; Davis, R. P. Frontiers in Pharmacology 2011, 2.

54. Albright, A. L.; Awaad, Y.; Muhonen, M.; Boydston, W. R.; Gilmartin, R.; Krach, L. E.; Turner, M.; Zidek, K. A.; Wright, E.; Swift, D.; Bloom, K. Journal of Neurosurgery 2004, 101, (1), 64.

55. Gilmartin, R.; Bruce, D.; Storrs, B. B.; Abbott, R.; Krach, L.; Ward, J.; Bloom, K.; Brooks, W. H.; Johnson, D. L.; Madsen, J. R.; McLaughlin, J. F.; Nadell, J. Journal of Child Neurology 2000, 15, (2), 71.

56. Baert, L.; Schueller, L.; Tardy, Y.; Macbride, D.; van't Klooster, G.; Borghys, H.; Clessens, E.; Van den Mooter, G.; Van Gyseghem, E.; Van Remoortere, P.; Wigerinck, P.; Rosier, J. International Journal of Pharmaceutics 2008, 355, (1-2), 38.

57. Ethans, K. D.; Schryvers, O. I.; Nance, P. W.; Casey, A. R. Spinal Cord 2005, 43, (4), 214.

58. Kemeny, N.; Seiter, K.; Niedzwiecki, D.; Chapman, D.; Sigurdson, E.; Cohen, A.; Botet, J.; Oderman, P.; Murray, P. Cancer 1992, 69, (2), 327.

59. Selam, J. L.; Micossi, P.; Dunn, F. L.; Nathan, D. M.; Fogel, H.; Gaz, R.; Haggen, C.; McKitrick, C.; Larkin, M.; Dunn, F.; Lavintomplins, J.; Thompson, M.; Byrd, P.; Sakiewicz, L.; Grant, J.; Selam, J. L.; Charles, M. A.; Waxman, K.; Raccah, D.; Jeandidier, N.; Lozano, J.; Micossi, P.; Cristallo, M.; Galimberti, G.; Petrella, G.; Librenti, M. C.; Scavini, M.; Pozza, G.; Bucci, V.; Wingrove, T.; Cafferty, M.; Day, J.; Sarmiento, M.; Blackshear, P. Diabetes Care 1992, $15,(7), 877$.

60. Anderson, S. M.; Raghinaru, D.; Pinsker, J. E.; Boscari, F.; Renard, E.; Buckingham, B. A.; Nimri, R.; Doyle, F. J.; Brown, S. A.; Keith-Hynes, P.; Breton, M. D.; Chernavvsky, D.; Bevier, W. C.; Bradley, P. K.; Bruttomesso, D.; Del Favero, S.; Calore, R.; Cobelli, C.; Avogaro, A.; Farret, A.; Place, J.; Ly, T. T.; Shanmugham, S.; Phillip, M.; Dassau, E.; Dasanayake, I. S.; Kollman, C.; Lum, J. W.; Beck, R. W.; Kovatchev, B.; Control Range Study, G. Diabetes Care 2016, 39, (7), 1143.

61. Pickup, J.; Mattock, M.; Kerry, S. British Medical Journal 2002, 324, (7339), 705.

62. Blauw, H.; van Bon, A. C.; Koops, R.; DeVries, J. H.; Consortium, P. Diabetes Obesity \& Metabolism 2016, 18, (7), 671.

63. Ramotowska, A.; Szypowska, A. Diabetes-Metabolism Research and Reviews 2014, 30, (2), 146.

64. Kovatchev, B.; Cheng, P. Y.; Anderson, S. M.; Pinsker, J. E.; Boscari, F.; Buckingham, B. A.; Doyle, F. J.; Hood, K. K.; Brown, S. A.; Breton, M. D.; Chernavvsky, D.; Bevier, W. C.; Bradley, P. K.; Bruttomesso, D.; Del Favero, S.; Calore, R.; Cobelli, C.; Avogaro, A.; Ly, T. T.; Shanmugham, S.; Dassau, E.; Kollman, C.; Lum, J. W.; Beck, R. W.; Control Range Study, G. Diabetes Technology \& Therapeutics 2017, 19, (1), 18. 65. Bottros, M. M.; Christo, P. J. Journal of Pain Research 2014, 7, 615. 66. Brache, V.; Payan, L. J.; Faundes, A. Contraception 2013, 87, (3), 264. 67. Huang, Y. M.; Merkatz, R. B.; Hillier, S. L.; Roberts, K.; Blithe, D. L.; Sitruk-Ware, R.; Creinin, M. D. Plos One 2015, 10, (8).

68. Hubacher, D.; Lara-Ricalde, R.; Taylor, D. J.; Guerra-Infante, F.; Guzman-Rodriguez, R. New England Journal of Medicine 2001, 345, (8), 561. 

57, (11), 1314.

70. Jaworska, J.; Jelonek, K.; Sobota, M.; Kasperczyk, J.; Dobrzynski, P.; Musial-Kulik, M.; Smola-Dmochowska, A.; Janeczek, H.; Jarzabek, B. J. Appl. Polym. Sci. 2015, 132, (17). 71. Katz, G.; Harchandani, B.; Shah, B. Current Atherosclerosis Reports 2015, 17, (3). 72. Wache, H. M.; Tartakowska, D. J.; Hentrich, A.; Wagner, M. H. Journal of Materials Science-Materials in Medicine 2003, 14, (2), 109. Whittle, I. R.; Jaaskelainen, J.; Ram, Z. Neuro-Oncology 2003, 5, (2), 79. 74. Westphal, M.; Ram, Z.; Riddle, V.; Hilt, D.; Bortey, E.; Executive Comm Gliadel Study, G. Acta Neurochirurgica 2006, 148, (3), 269.

858 75. Saher, O.; Ghorab, D. M.; Mursi, N. M. Journal of Drug Delivery Science and 859 Technology 2016, 31, 22.

860 76. Gulsen, D.; Chauhan, A. Investigative Ophthalmology \& Visual Science 2004, 45, (7),

\section{2.}

862 77. Jain, M. R. British Journal of Ophthalmology 1988, 72, (2), 150.

863 78. Kim, J.; Conway, A.; Chauhan, A. Biomaterials 2008, 29, (14), 2259.

864 79. Kim, J.; Chauhan, A. Abstracts of Papers of the American Chemical Society 2008, 235.

865 80. Dong, L. C.; Hoffman, A. S. Journal of Controlled Release 1991, 15, (2), 141.

866 81. Goyanes, A.; Fina, F.; Martorana, A.; Sedough, D.; Gaisford, S.; Basit, A. W.

867 International Journal of Pharmaceutics 2017, 527, (1-2), 21.

868 82. Park, H. J.; Jung, H. J.; Ho, M. J.; Lee, D. R.; Cho, H. R.; Choi, Y. S.; Jun, J.; Son, M.; 869 Kang, M. J. European Journal of Pharmaceutical Sciences 2017, 102, 172.

$870 \quad$ 83. Kim, J.; Li, W. A.; Choi, Y.; Lewin, S. A.; Verbeke, C. S.; Dranoff, G.; Mooney, D. J. $871 \quad$ Nat Biotechnol 2015, 33, (1), 64.

$872 \quad$ 84. Kim, J.; Mooney, D. J. Nano Today 2011, 6, (5), 466.

873 85. Li, W. A.; Mooney, D. J. Current Opinion in Immunology 2013, 25, (2), 238.

874 86. Dobnig, H.; Turner, R. T. Endocrinology 1997, 138, (11), 4607.

875 87. Waterman, K. C.; Goeken, G. S.; Konagurthu, S.; Likar, M. D.; MacDonald, B. C.; 876 Mahajan, N.; Swaminathan, V. Journal of Controlled Release 2011, 152, (2), 264.

877 88. $\quad$ Arya, J.; Prausnitz, M. R. Journal of Controlled Release 2016, $240,135$.

878 89. Baek, S. H.; Shin, J. H.; Kim, Y. C. Biomedical Microdevices 2017, 19, (1), 11.

879 90. Chandrasekhar, S.; Iyer, L. K.; Panchal, J. P.; Topp, E. M.; Cannon, J. B.; Ranade, V. 880 V. Expert Opinion on Drug Delivery 2013, 10, (8), 1155.

881 91. Ma, G. J.; Wu, C. W. Journal of Controlled Release 2017, 251, 11.

882 92. Yu, J. C.; Zhang, Y. Q.; Ye, Y. Q.; DiSanto, R.; Sun, W. J.; Ranson, D.; Ligler, F. S.;

883 Buse, J. B.; Gu, Z. Proceedings of the National Academy of Sciences of the United States of 884 America 2015, 112, (27), 8260.

885 93. Ferris, R. L.; Lotze, M. T.; Leong, S. P. L.; Hoon, D. S. B.; Morton, D. L. Clinical \& 886 Experimental Metastasis 2012, 29, (7), 729.

887 94. Margaris, K. N.; Black, R. A. Journal of the Royal Society Interface 2012, 9, (69), 601.

888 95. Potter, R. F.; Groom, A. C. Microvascular Research 1983, 25, (1), 68.

889 96. Santini, J. T.; Cima, M. J.; Langer, R. Nature 1999, 397, (6717), 335.

890 97. Elman, N. M.; Duc, H. L. H.; Cima, M. J. Biomedical Microdevices 2009, 11, (3), 625.

891 98. Goffredo, R.; Pecora, A.; Maiolo, L.; Ferrone, A.; Guglielmelli, E.; Accoto, D. J.

892 Microelectromech. Syst. 2016, 25, (2), 362.

893 99. Lo, R.; Li, P. Y.; Saati, S.; Agrawal, R. N.; Humayun, M. S.; Meng, E. Biomedical 894 Microdevices 2009, 11, (5), 959.

895 100. Meng, E.; Hoang, T. Advanced Drug Delivery Reviews 2012, 64, (14), 1628.

896 101. Nguyen, C. T. C. Ieee Transactions on Ultrasonics Ferroelectrics and Frequency 897 Control 2007, 54, (2), 251.

898 102. Nguyen, C. T. C. Ieee Transactions on Microwave Theory and Techniques 1999, 47, 899 (8), 1486. 

Technology of Advanced Materials 2015, 16, (1).

104. Tsai, N. C.; Sue, C. Y. Sensors and Actuators a-Physical 2007, 134, (2), 555.

105. Zordan, E.; Amirouche, F. Proceedings of the Institution of Mechanical Engineers Part H-Journal of Engineering in Medicine 2007, 221, (H2), 143.

106. Huesgen, T.; Lenk, G.; Albrecht, B.; Vulto, P.; Lemke, T.; Woias, P. Sensors and Actuators a-Physical 2010, 162, (1), 137.

107. Johnson, D. G.; Borkholder, D. A. Micromachines 2016, 7, (6), 16.

108. Nguyen, N. T.; Huang, X. Y.; Chuan, T. K. Journal of Fluids Engineering-Transactions of the Asme 2002, 124, (2), 384.

$910109 . \quad$ Pirmoradi, F. N.; Jackson, J. K.; Burt, H. M.; Chiao, M. Lab on a Chip 2011, 11, (16),

9112744.

912 110. Zainal, M. A.; Ahmad, A.; Ali, M. S. M. Biomedical Microdevices 2017, 19, (1), 10.

913 111. Gill, H. S.; Prausnitz, M. R. J Diabetes Sci Technol 2007, 1, (5), 725.

914 112. Jalil, R. U. Drug Development and Industrial Pharmacy 1990, 16, (16), 2353.

915

916

917

918

919

920

921

922

923

924

925

926

927

928

929

930

931

932

933

934

935

936

937

938

939

940

941

942

943

944

113. Gong, C.; Qi, T.; Wei, X.; Qu, Y.; Wu, Q.; Luo, F.; Qian, Z. Current Medicinal Chemistry 2013, 20, (1), 79.

114. Kurisawa, M.; Chung, J. E.; Yang, Y. Y.; Gao, S. J.; Uyama, H. Chem Commun 2005, (34), 4312.

115. Sun, J. E. P.; Stewart, B.; Litan, A.; Lee, S. J.; Schneider, J. P.; Langhans, S. A.;

Pochan, D. J. Biomaterials Science 2016, 4, (5), 839.

116. Yan, C. Q.; Altunbas, A.; Yucel, T.; Nagarkar, R. P.; Schneider, J. P.; Pochan, D. J. Soft Matter 2010, 6, (20), 5143.

117. Ye, H. Y.; Owh, C.; Jiang, S.; Ng, C. Z. Q.; Wirawan, D.; Loh, X. J. Polymers 2016, 8, (4).

118. Brudno, Y.; Mooney, D. J. Journal of Controlled Release 2015, 219, 8.

119. Brudno, Y.; Silva, E. A.; Kearney, C. J.; Lewin, S. A.; Miller, A.; Martinick, K. D.; Aizenberg, M.; Mooney, D. J. Proceedings of the National Academy of Sciences of the United States of America 2014, 111, (35), 12722.

120. Acharya, A. P.; Lewis, J. S.; Keselowsky, B. G. Biomaterials 2013, 34, (13), 3422.

121. Rafati, A.; Boussahel, A.; Shakesheff, K. M.; Shard, A. G.; Roberts, C. J.; Chen, X.; Scurr, D. J.; Rigby-Singleton, S.; Whiteside, P.; Alexander, M. R.; Davies, M. C. Journal of Controlled Release 2012, 162, (2), 321.

122. Rahimian, S.; Fransen, M. F.; Kleinovink, J. W.; Amidi, M.; Ossendorp, F.; Hennink, W. E. Current Pharmaceutical Design 2015, 21, (29), 4201.

123. Wang, N. X.; Bazdar, D. A.; Sieg, S. F.; von Recum, H. A. Biotechnol. Bioeng. 2012, $109,(7), 1835$.

124. White, L. J.; Kirby, G. T. S.; Cox, H. C.; Qodratnama, R.; Qutachi, O.; Rose, F.; Shakesheff, K. M. Materials Science \& Engineering C-Materials for Biological Applications 2013, 33, (5), 2578.

125. Xia, Y. J.; Pack, D. W. Chemical Engineering Science 2015, 125, 129.

126. Goldray, D.; Weisman, Y.; Jaccard, N.; Merdler, C.; Chen, J.; Matzkin, H. Journal of Clinical Endocrinology \& Metabolism 1993, 76, (2), 288.

127. Parmar, H.; Rustin, G.; Lightman, S. L.; Phillips, R. H.; Hanham, I. W.; Schally, A. V. British Medical Journal 1988, 296, (6631), 1229.

128. De Leede, L. G. J.; Humphries, J. E.; Bechet, A. C.; Van Hoogdalem, E. J.; Verrijk, R.; Spencer, D. G. J. Interferon Cytokine Res. 2008, 28, (2), 113.

Langer, R.; Jaklenec, A. Journal of Controlled Release 2016, 233, 101.

949 130. Farra, R.; Sheppard, N. F.; McCabe, L.; Neer, R. M.; Anderson, J. M.; Santini, J. T.;

950 Cima, M. J.; Langer, R. Science translational medicine 2012, 4, (122).

951 131. Jonas, O.; Calligaris, D.; Methuku, K. R.; Poe, M. M.; Francois, J. P.; Tranghese, F.;

952 Changelian, A.; Sieghart, W.; Ernst, M.; Krummel, D. A. P.; Cook, J. M.; Pomeroy, S. L.;

953 Cima, M.; Agar, N. Y. R.; Langer, R.; Sengupta, S. Journal of Biomedical Nanotechnology

954 2016, 12, (6), 1297. 
132. Jonas, O.; Landry, H. M.; Fuller, J. E.; Santini, J. T.; Baselga, J.; Tepper, R. I.; Cima, M. J.; Langer, R. Science translational medicine 2015, 7, (284).

133. Nature Reviews Drug Discovery 2008, 7, (12), 964.

958

959

134. Champion, J. A.; Katare, Y. K.; Mitragotri, S. Journal of Controlled Release 2007, 121, (1-2), 3 .

960

961

135. Mandal, S.; Hammink, R.; Tel, J.; Eksteen-Akeroyd, Z. H.; Rowan, A. E.; Blank, K.; Figdor, C. G. ACS Chem. Bio. 2015, 10, (2), 485.

962 136. Meyer, R. A.; Sunshine, J. C.; Green, J. J. Trends Biotechnol. 2015, 33, (9), 514.

963 137. Perica, K.; Kosmides, A. K.; Schneck, J. P. Biochim. Phys. Acta. 2015, 1853, (4), 781.

964 138. Veiseh, O.; Doloff, J. C.; Ma, M.; Vegas, A. J.; Tam, H. H.; Bader, A. R.; Li, J.;

965 Langan, E.; Wyckoff, J.; Loo, W. S.; Jhunjhunwala, S.; Chiu, A.; Siebert, S.; Tang, K.;

966 Hollister-Lock, J.; Aresta-Dasilva, S.; Bochenek, M.; Mendoza-Elias, J.; Wang, Y.; Qi, M.;

967 Lavin, D. M.; Chen, M.; Dholakia, N.; Thakrar, R.; Lacik, I.; Weir, G. C.; Oberholzer, J.;

968 Greiner, D. L.; Langer, R.; Anderson, D. G. Nat. Mater. 2015, 14, (6), 643.

969

970

971

972

973

974

975

976

977

978 139. Bencherif, S. A.; Sands, R. W.; Bhatta, D.; Arany, P.; Verbeke, C. S.; Edwards, D. A.; Mooney, D. J. Proceedings of the National Academy of Sciences of the United States of America 2012, 109, (48), 19590.

140. Sun, L.; Huang, W. M.; Ding, Z.; Zhao, Y.; Wang, C. C.; Purnawali, H.; Tang, C. Materials \& Design 2012, 33, 577.

141. Wang, L.; Shansky, J.; Borselli, C.; Mooney, D.; Vandenburgh, H. Tissue Eng. Part A 2012, 18, (19-20), 2000.

142. Chirra, H. D.; Desai, T. A. Small 2012, 8, (24), 3839.

143. Wischke, C.; Zimmermann, J.; Wessinger, B.; Schendler, A.; Borchert, H. H.; Peters, J. H.; Nesselhut, T.; Lorenzen, D. R. International Journal of Pharmaceutics 2009, 365, (1-2), 61.

979 144. Rudd, P. M.; Wormald, M. R.; Stanfield, R. L.; Huang, M. D.; Mattsson, N.; Speir, J.

980 A.; DiGennaro, J. A.; Fetrow, J. S.; Dwek, R. A.; Wilson, I. A. J. Mol. Biol. 1999, 293 , (2), 351.

981 145. Liang, H. F.; Chen, C. T.; Chen, S. C.; Kulkarni, A. R.; Chiu, Y. L.; Chen, M. C.; Sung, 982 H. W. Biomaterials 2006, 27, (9), 2051.

983 146. Lewis, J. S.; Dolgova, N. V.; Zhang, Y.; Xia, C. Q.; Wasserfall, C. H.; Atkinson, M. A.;

984

985

986

987

988

989 Clare-Salzler, M. J.; Keselowsky, B. G. Clinical Immunology 2015, 160, (1), 90.

147. Yoon, Y. M.; Lewis, J. S.; Carstens, M. R.; Campbell-Thompson, M.; Wasserfall, C. H.; Atkinson, M. A.; Keselowsky, B. G. Scientific Reports 2015, 5.

148. Bull, J. L. Expert Opinion on Drug Delivery 2007, 4, (5), 475.

149. Ren, S. T.; Liao, Y. R.; Kang, X. N.; Li, Y. P.; Zhang, H.; Ai, H.; Sun, Q.; Jing, J.;

Zhao, X. H.; Tan, L. F.; Shen, X. L.; Wang, B. Pharmaceutical Research 2013, 30, (6), 1574.

990 150. Wu, S. Z.; Li, L.; Wang, G.; Shen, W. W.; Xu, Y. L.; Liu, Z.; Zhuo, Z. X.; Xia, H. M.; Gao, Y. H.; Tan, K. B. International Journal of Nanomedicine 2014, 9, 5639.

992 151. Kost, J.; Leong, K.; Langer, R. Proceedings of the National Academy of Sciences of the 993 United States of America 1989, 86, (20), 7663.

994 152. Mitragotri, S.; Blankschtein, D.; Langer, R. Science 1995, 269, (5225), 850.

995 153. Nature Nanotechnology 2009, 4, (3), 135.

996 154. Sheikh, Z.; Brooks, P. J.; Barzilay, O.; Fine, N.; Glogauer, M. Materials 2015, 8, (9),

155. Kaczmarek, J. C.; Patel, A. K.; Kauffman, K. J.; Fenton, O. S.; Webber, M. J.; Heartlein, M. W.; DeRosa, F.; Anderson, D. G. Angewandte Chemie-International Edition 2016, 55, (44), 13808.

156. Zhou, D. Z.; Gao, Y. S.; Ahern, J. O.; Sigen, A.; Xu, Q.; Huang, X. B.; Greiser, U.; Wang, W. X. Acs Applied Materials \& Interfaces 2016, 8, (50), 34218.

157. Felnerova, D.; Viret, J. F.; Gluck, R.; Moser, C. Current Opinion in Biotechnology 2004, 15, (6), 518.

1005

1006 158. Boswell, G. W.; Bekersky, I.; Buell, D.; Hiles, R.; Walsh, T. J. Antimicrobial Agents and Chemotherapy 1998, 42, (2), 263.

1007 159. Boswell, G. W.; Buell, D.; Bekersky, I. Journal of Clinical Pharmacology 1998, 38, 1008 (7), 583. 
160. Walsh, T. J.; Yeldandi, V.; McEvoy, M.; Gonzalez, C.; Chanock, S.; Freifeld, A.; Seibel, N. I.; Whitcomb, P. O.; Jarosinski, P.; Boswell, G.; Bekersky, I.; Alak, A.; Buell, D.; Barret, J.; Wilson, W. Antimicrobial Agents and Chemotherapy 1998, 42, (9), 2391.

161. Sheu, M. T.; Chen, S. Y.; Chen, L. C.; Ho, H. O. Journal of Controlled Release 2003, $88,(3), 355$.

162. Soo, P. L.; Lovric, J.; Davidson, P.; Maysinger, D.; Eisenberg, A. Molecular Pharmaceutics 2005, 2, (6), 519.

163. Chiechi, L. M. Idrugs 2004, 7, (9), 860.

164. Ishida, T.; Atobe, K.; Wang, X. Y.; Kiwada, H. Journal of Controlled Release 2006, $115,(3), 251$.

165. Nellis, D. F.; Giardina, S. L.; Janini, G. M.; Shenoy, S. R.; Marks, J. D.; Tsai, R.; Drummond, D. C.; Hong, K.; Park, J. W.; Ouellette, T. F.; Perkins, S. C.; Kirpotin, D. B. Biotechnology Progress 2005, 21, (1), 221.

166. Sekine, Y.; Moritani, Y.; Ikeda-Fukazawa, T.; Sasaki, Y.; Akiyoshi, K. Advanced Healthcare Materials 2012, 1, (6), 722.

167. Zhang, C. Y.; Yang, Y. Q.; Huang, T. X.; Zhao, B.; Guo, X. D.; Wang, J. F.; Zhang, L. J. Biomaterials 2012, 33, (26), 6273.

168. Ganson, N. J.; Povsic, T. J.; Sullenger, B. A.; Alexander, J. H.; Zelenkofske, S. L.; Sailstad, J. M.; Rusconi, C. P.; Hershfield, M. S. Journal of Allergy and Clinical Immunology 2016, 137, (5), 1610.

169. Chiappini, C.; De Rosa, E.; Martinez, J. O.; Liu, X.; Steele, J.; Stevens, M. M.; Tasciotti, E. Nature materials 2015, 14, (5), 532. 170. Serda, R. E.; Godin, B.; Blanco, E.; Chiappini, C.; Ferrari, M. Biochimica Et Biophysica Acta-General Subjects 2011, 1810, (3), 317. 171. Shalek, A. K.; Robinson, J. T.; Karp, E. S.; Lee, J. S.; Ahn, D. R.; Yoon, M. H.; Sutton, A.; Jorgolli, M.; Gertner, R. S.; Gujral, T. S.; MacBeath, G.; Yang, E. G.; Park, H. Proceedings of the National Academy of Sciences of the United States of America 2010, 107, (5), 1870.

172. Fischer, K. E.; Aleman, B. J.; Tao, S. L.; Daniels, R. H.; Li, E. M.; Bunger, M. D.; Nagaraj, G.; Singh, P.; Zettl, A.; Desai, T. A. Nano Letters 2009, 9, (2), 716.

173. Brammer, K. S.; Choi, C.; Oh, S.; Cobb, C. J.; Connelly, L. S.; Loya, M.; Kong, S. D.; Jin, S. Nano Letters 2009, 9, (10), 3570.

174. Uskokovic, V.; Lee, P. P.; Walsh, L. A.; Fischer, K. E.; Desai, T. A. Biomaterials 2012, 33, (5), 1663.

175. Bianco, A.; Kostarelos, K.; Prato, M. Current Opinion in Chemical Biology 2005, 9 , (6), 674.

176. Fadel, T. R.; Sharp, F. A.; Vudattu, N.; Ragheb, R.; Garyu, J.; Kim, D.; Hong, E.; Li, N.; Haller, G. L.; Pfefferle, L. D.; Justesen, S.; Herold, K. C.; Fahmy, T. M. Nat. Nanotechnol. 2014, 9, (8), 639.

1047 177. Li, D. D.; Kordalivand, N.; Fransen, M. F.; Ossendorp, F.; Raemdonck, K.; Vermonden, T.; Hennink, W. E.; van Nostrum, C. F. Adv. Funct. Mater. 2015, 25, (20), 2993.

178. Naeye, B.; Raemdonck, K.; Remaut, K.; Sproat, B.; Demeester, J.; De Smedt, S. C. European Journal of Pharmaceutical Sciences 2010, 40, (4), 342.

179. Raemdonck, K.; Demeester, J.; De Smedt, S. Soft Matter 2009, 5, (4), 707.

180. Van Thienen, T. G.; Demeester, J.; De Smedt, S. C. International Journal of Pharmaceutics 2008, 351, (1-2), 174.

181. Kong, I. G.; Sato, A.; Yuki, Y.; Nochi, T.; Takahashi, H.; Sawada, S.; Mejima, M.; Kurokawa, S.; Okada, K.; Sato, S.; Briles, D. E.; Kunisawa, J.; Inoue, Y.; Yamamoto, M.; Akiyoshi, K.; Kiyono, H. Infection and Immunity 2013, 81, (5), 1625.

182. Nochi, T.; Yuki, Y.; Takahashi, H.; Sawada, S.; Mejima, M.; Kohda, T.; Harada, N.; Kong, I. G.; Sato, A.; Kataoka, N.; Tokuhara, D.; Kurokawa, S.; Takahashi, Y.; Tsukada, H.; Kozaki, S.; Akiyoshi, K.; Kiyono, H. Nature materials 2010, 9, (7), 572. 183. Yarmolenko, P. S.; Zhao, Y. L.; Landon, C.; Spasojevic, I.; Yuan, F.; Needham, D.; Viglianti, B. L.; Dewhirst, M. W. International Journal of Hyperthermia 2010, 26, (5), 485. 184. Blinder, K. J.; Blumenkranz, M. S.; Bressler, N. M.; Bressler, S. B.; Donati, G.; Lewis, H.; Lim, J. I.; Menchini, U.; Miller, J. W.; Mones, J. M.; Potter, M. J.; Pournaras, C.; Reaves, 
A.; Rosenfeld, P.; Schachat, A. P.; Schmidt-Erfurth, U.; Sickenberg, M.; Singerman, L. J.; Slakter, J.; Strong, H. A.; Virgili, G.; Williams, G. A.; Grp, V. I. P. S. Ophthalmology 2003, 110, (4), 667.

185. Spaide, R. F.; Sorenson, J.; Maranan, L. Ophthalmology 2003, 110, (8), 1517.

186. Matsumura, Y.; Maeda, H. Cancer Research 1986, 46, (12), 6387.

187. Ogris, E.; Mudrak, I.; Mak, E.; Gibson, D.; Pallas, D. C. Journal of Virology 1999, 73, (9), 7390.

1071

188. Ogris, M.; Brunner, S.; Schuller, S.; Kircheis, R.; Wagner, E. Gene Therapy 1999, 6, 1072 (4), 595.

1073 189. Kreuter, J.; Shamenkov, D.; Petrov, V.; Ramge, P.; Cychutek, K.; Koch-Brandt, C.;

1074 Alyautdin, R. Journal of Drug Targeting 2002, 10, (4), 317.

1075 190. Akinc, A.; Querbes, W.; De, S. M.; Qin, J.; Frank-Kamenetsky, M.; Jayaprakash, K. N.;

1076 Jayaraman, M.; Rajeev, K. G.; Cantley, W. L.; Dorkin, J. R.; Butler, J. S.; Qin, L. L.; Racie, T.;

1077 Sprague, A.; Fava, E.; Zeigerer, A.; Hope, M. J.; Zerial, M.; Sah, D. W. Y.; Fitzgerald, K.;

1078 Tracy, M. A.; Manoharan, M.; Koteliansky, V.; de Fougerolles, A.; Maier, M. A. Molecular 1079 Therapy 2010, 18, (7), 1357.

1080 191. Semple, S. C.; Akinc, A.; Chen, J. X.; Sandhu, A. P.; Mui, B. L.; Cho, C. K.; Sah, D.

1081 W. Y.; Stebbing, D.; Crosley, E. J.; Yaworski, E.; Hafez, I. M.; Dorkin, J. R.; Qin, J.; Lam, K.;

1082 Rajeev, K. G.; Wong, K. F.; Jeffs, L. B.; Nechev, L.; Eisenhardt, M. L.; Jayaraman, M.; Kazem,

1083 M.; Maier, M. A.; Srinivasulu, M.; Weinstein, M. J.; Chen, Q. M.; Alvarez, R.; Barros, S. A.;

1084 De, S.; Klimuk, S. K.; Borland, T.; Kosovrasti, V.; Cantley, W. L.; Tam, Y. K.; Manoharan, M.;

1085 Ciufolini, M. A.; Tracy, M. A.; de Fougerolles, A.; MacLachlan, I.; Cullis, P. R.; Madden, T.

1086 D.; Hope, M. J. Nat Biotechnol 2010, 28, (2), 172.

1087 192. Blanco, E.; Shen, H.; Ferrari, M. Nat Biotechnol 2015, 33, (9), 941.

1088 193. Rodriguez, P. L.; Harada, T.; Christian, D. A.; Pantano, D. A.; Tsai, R. K.; Discher, D. 1089 E. Science 2013,339, (6122), 971.

1090 194. Daniels-Wells, T. R.; Penichet, M. L. Immunotherapy 2016, 8, (9), 991.

1091 195. Nobs, L.; Buchegger, F.; Gurny, R.; Allemann, E. Bioconjugate Chemistry 2006, 17, 1092 (1), 139.

1093 196. Desai, N.; Trieu, V.; Yao, Z. Clinical Cancer Research 2006, 12, (12), 3869.

1094 197. Desai, N. P.; Trieu, V.; Hwang, L. Y.; Wu, R. J.; Soon-Shiong, P.; Gradishar, W. J.

1095 Anti-Cancer Drugs 2008, 19, (9), 899.

1096 198. Ng, S. S. W.; Sparreboom, A.; Shaked, Y.; Lee, C.; Man, S.; Desai, N.; Soon-Shiong,

1097 P.; Figg, W. D.; Kerbel, R. S. Clinical Cancer Research 2006, 12, (14), 4331.

1098 199. Karagiannis, E. D.; Urbanska, A. M.; Sahay, G.; Pelet, J. M.; Jhunjhunwala, S.; Langer, 1099 R.; Anderson, D. G. Acs Nano 2013, 7, (10), 8616.

1100 200. LaVan, D. A.; McGuire, T.; Langer, R. Nat Biotechnol 2003, 21, (10), 1184.

1101 201. Bellinger, A. M.; Jafari, M.; Grant, T. M.; Zhang, S. Y.; Slater, H. C.; Wenger, E. A.;

1102 Mo, S.; Lee, Y. A. L.; Mazdiyasni, H.; Kogan, L.; Barman, R.; Cleveland, C.; Booth, L.;

1103 Bensel, T.; Minahan, D.; Hurowitz, H. M.; Tai, T.; Daily, J.; Nikolic, B.; Wood, L.; Eckhoff, P.

1104 A.; Langer, R.; Traverso, G. Science translational medicine 2016, 8, (365).

1105 202. C. Di Mario, H. G., O. Goktekin, N. Peeters, J. Verbist, M. Bosiers, K. Deloose, B.

1106 Heublein, R. Rohde, V. Kasese, C. Ilsley, R. Erbel. Journal of Interventional Cardiology 2004, 1107 17, (6), 391.

1108 